\title{
Scavenger Receptors: Novel Roles in the Pathogenesis of Liver Inflammation and Cancer
}

\author{
Daniel A. Patten, BSc, PhD ${ }^{1,2, *}$ Alex L. Wilkinson, BSc, MRes ${ }^{1,2, *}$ Ayla O’Keeffe, BSc, MRes ${ }^{1,2}$ \\ Shishir Shetty, MBChB, PhD, FRCP ${ }^{1,2}$
}

\author{
${ }^{1}$ National Institute for Health Research Birmingham Liver Biomedical \\ Research Unit, Institute of Immunology and Immunotherapy, \\ University of Birmingham, Birmingham, United Kingdom \\ ${ }^{2}$ Centre for Liver and Gastrointestinal Research, Institute of \\ Immunology and Immunotherapy, University of Birmingham, \\ Birmingham, United Kingdom
}

Address for correspondence Shishir Shetty, MBChB, PhD, FRCP, National Institute for Health Research Birmingham Liver Biomedical Research Unit and Centre for Liver and Gastrointestinal Research, Institute of Immunology and Immunotherapy, University of Birmingham, Birmingham B15 2TT, United Kingdom (e-mail: s.shetty@bham.ac.uk).

\author{
Abstract \\ Keywords \\ - scavenger receptors \\ - macrophages \\ - liver sinusoidal \\ endothelial cells \\ - cirrhosis \\ - hepatocellular \\ carcinoma
}

The scavenger receptor superfamily represents a highly diverse collection of evolutionarily-conserved receptors which are known to play key roles in host homeostasis, the most prominent of which is the clearance of unwanted endogenous macromolecules, such as oxidized low-density lipoproteins, from the systemic circulation. Members of this family have also been well characterized in their binding and internalization of a vast range of exogenous antigens and, consequently, are generally considered to be pattern recognition receptors, thus contributing to innate immunity. Several studies have implicated scavenger receptors in the pathophysiology of several inflammatory diseases, such as Alzheimer's and atherosclerosis. Hepatic resident cellular populations express a diverse complement of scavenger receptors in keeping with the liver's homeostatic functions, but there is gathering interest in the contribution of these receptors to hepatic inflammation and its complications. Here, we review the expression of scavenger receptors in the liver, their functionality in liver homeostasis, and their role in inflammatory liver disease and cancer.

\section{Liver Disease Pathophysiology}

Liver disease is one of the leading causes of mortality in the United Kingdom, with cirrhosis becoming one of the top three causes of premature death in people aged 30 to 60 years. ${ }^{1}$ Damage to the liver may originate from viral, metabolic, autoimmune, or toxin-induced pathways and etiologies differ depending on the site of injury. For example, nonalcoholic fatty liver disease (NAFLD)/nonalcoholic steatohepatitis (NASH) is initiated by lipotoxic damage to hep-

* These authors contributed equally to this work.

published online

September 22, 2021
DOI https://doi.org/

$10.1055 / \mathrm{s}-0041-1733876$.

ISSN 0272-8087. atocytes, ${ }^{2}$ whereas primary sclerosing cholangitis arises from damage to cholangiocytes and leads to stricturing of bile ducts. ${ }^{3}$ Nevertheless, regardless of etiology, most chronic adult liver diseases follow a common progressive pathophysiology in which persistent inflammation of the liver leads to the activation of hepatic stellate cells (HSCs), which in turn results in excessive production of extracellular matrix (ECM) proteins, leading to fibrosis, impaired liver function, and eventually cirrhosis. ${ }^{4}$

Due to its increasing prevalence, chronic liver disease is fast becoming a serious global health burden. ${ }^{5,6}$ In addition, chronic inflammatory disease significantly increases the risk

\footnotetext{
(c) 2021. The Author(s).

This is an open access article published by Thieme under the terms of the Creative Commons Attribution License, permitting unrestricted use, distribution, and reproduction so long as the original work is properly cited. (https://creativecommons.org/licenses/by/4.0/)

Thieme Medical Publishers, Inc., 333 Seventh Avenue, 18th Floor,
} New York, NY 10001, USA 
of liver failure or hepatocellular carcinoma (HCC), with up to $90 \%$ of HCC cases arising on a background of cirrhosis. ${ }^{7}$ Consequently, liver cancer is the seventh most common cancer worldwide and the fourth most common cause of cancer-related mortality. ${ }^{8}$ Approximately three-quarters of all chronic liver diseases are diagnosed at a late stage when lifestyle interventions would be insufficient and there is also a distinct lack of effective treatments currently available for HCC; therefore, in both instances, transplantation is the only curative therapy. However, transplantation is clearly a major intervention with strict criteria and therefore is only considered a viable option in a minority of HCC patients. Those with advanced HCC have no curative options and despite the advent of immunotherapy, the majority of patients do not respond to current treatment. Consequently, there is an urgent need to better understand the inflammatory pathways and processes that contribute to liver disease progression so that novel targets may be identified and utilized.

Owing to its anatomical positioning in close association with the gastrointestinal tract, and frequently exposed to the vast milieu of gut-derived antigenic materials, the liver and its resident cell types express a wide array of scavenger receptors which are known to play key roles in homeostasis. In addition, there is now increasing evidence that scavenger receptors also play a diverse range of roles in inflammatory diseases of the liver and significantly contribute to their pathophysiology. In this review, we discuss the expression of scavenger receptors by various hepatic cells types, and their contribution to maintaining homeostasis and driving the pathogenesis of inflammatory liver disease and cancer.

\section{Scavenger Receptors}

Scavenger receptors are a diverse superfamily of evolutionarily-conserved receptors that play an important role in homeostatic processes, including nutrient exchange and waste clearance, and in immunity, such as inflammation regulation, leukocyte adhesion, and antigen presentation. ${ }^{9}$ First identified by their ability to bind modified lipoproteins, such as oxidized low-density lipoproteins (oxLDLs), ${ }^{10}$ scavenger receptors have now been shown to bind and/or internalize a diverse range of endogenous and exogenous ligands. ${ }^{11}$ As such, scavenger receptors are now considered to be a subcategory of pattern recognition receptors (PRRs). ${ }^{12}$ Scavenger receptors are categorized into classes A-J ( - Fig. 1) depending on their structural and functional properties; however, there is little/no sequence homology between classes. ${ }^{9}$

Although scavenger receptors are defined as cell-surface receptors, they may also be found intracellularly or as soluble forms in the circulation. ${ }^{9}$ They can bind to a variety of unwanted self and non-self ligands and promote their removal from the systemic circulation via endocytosis, phagocytosis, or macropinocytosis. ${ }^{9,11}$ Such ligands include damage-associated molecular patterns such as apoptotic cells, damaged proteins, cell debris, and heat shock proteins, and pathogen-associated molecular patterns, such as lipopolysaccharides (LPSs) and lipoteichoic acid. ${ }^{13}$ Thus, their role in maintaining homeostasis spans beyond the scaveng- ing of waste products, but rather, encompasses their ability to preserve appropriate levels of endogenous molecules while also recognizing foreign or damaging antigens and eliciting appropriate cellular immune responses.

The importance of scavenger receptors in homeostasis is highlighted by the complications that arise in their absence; for example, loss of functional SCARF1, SR-AI, or MARCO in transgenic mice leads to the development of systemic lupus erythematosus. ${ }^{14,15}$ In addition, several scavenger receptors have been shown to play a key regulatory role in disease pathology, limiting the extent of injury in murine models of inflammatory disease. For instance, genetic deletion of SCARB1 was shown to increase disease severity in a murine model of Alzheimer's ${ }^{16}$ and stabilin-1-deficient mice present with significantly more severe fibrosis in chronic liver injury models. ${ }^{17}$ Conversely, some scavenger receptors have also been shown to drive the pathogenesis of multiple inflammatory diseases, such as atherosclerosis. ${ }^{18,19}$

\section{Scavenger Receptors in Liver Homeostasis}

\section{Scavenging of Endogenous and Exogenous Macromolecules}

Scavenger receptors play a key role in maintaining homeostasis, particularly within the liver, which lies at the interface between the portal and systemic circulation. ${ }^{20}$ Due to its anatomical positioning, the liver is constantly exposed to a myriad of gut-derived nutrients and microbial antigens and, as a result, it functions as the body's primary metabolic and detoxification system. As such, the liver-resident cells and their vast array of endocytic receptors, such as scavenger receptors, are integral for the removal of both endogenous and exogenous macromolecules and waste material from the circulation. The majority of this function is undertaken by liver sinusoidal endothelial cells (LSECs). ${ }^{21}$

LSECs are highly specialized cells that line the liver sinusoids and represent the primary barrier between the bloodstream and underlying parenchymal tissues. Consequently, LSECs are adept scavengers, owing to their fenestrated morphology, lack of basement membrane, and superior endocytic capacity, and are involved in nutrient exchange, waste clearance, immune cell recruitment, and metabolism. ${ }^{22}$ The primary scavenger receptors of LSEC are considered to be stabilin-1 and stabilin-2, which principally target oxLDLs for degradation, ${ }^{23}$ amongst other macromolecules. Stabilin receptors (also known as FEEL/CLEVER/HARE) belong to the class $\mathrm{H}$ family of scavenger receptors, comprising a large extracellular N-terminus of 20 (stabilin-2) or 21 (stabilin-1) epidermal growth factor (EGF)/EGF-like domains, seven fasciclin-1 domains, and an X-linked domain, and a short intracellular C-terminal domain, linked by a transmembrane region ${ }^{24}$ (-Fig. 1). Despite sharing 55\% homology in their extracellular domains, these two receptors are distinguished by their highly diverse intracellular domains. $^{25}$ Although structurally distinct, both stabilin receptors mediate the specific hepatic uptake and clearance of oxLDLs by LSEC, an important mechanism for the prevention of atherogenesis. ${ }^{26}$ Studies using fluorescent or 


\begin{tabular}{|c|c|c|c|c|}
\hline Class & Structural Domains & Receptor Name(s) & Liver Cell Expression & Functional Role \\
\hline \multirow{2}{*}{$\mathbf{A}$} & \multirow{2}{*}{ 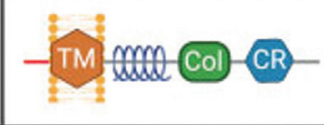 } & SR-AI, MSR1, SCARA1, SR-A1 & $\mathrm{M} \varphi, \mathrm{M} \emptyset, \mathrm{DC}, \mathrm{EC}$ & $\begin{array}{l}\text { PRR, Anti-inflammatory M } M \text { function, } \\
\text { free fatty acid uptake (NASH) }\end{array}$ \\
\hline & & MARCO, SCARA2, SR-A6 & $\mathrm{M} \varphi$ & PRR, HCC biomarker \\
\hline \multirow{2}{*}{ B } & & SCARB1, SR-BI, CD36L, SR-B1 & M $\varphi$, Hepatocytes & HDL receptor, HCV entry, NAFLD \\
\hline & & CD36, SCARB3, PAS4, SR-B2 & $M \varphi, M ø, ~ L S E C, ~ H S C$ & $\begin{array}{l}\text { Free fatty acid uptake, PRR, } \\
\text { M. bovis BCG infection }\end{array}$ \\
\hline D & & CD68, SR-D1 & $\mathrm{M} \varphi, \mathrm{M} \emptyset, \mathrm{TAM}$ & $\begin{array}{c}\text { PRR, oxLDL uptake, } \\
\text { P. berghei hepatic invasion }\end{array}$ \\
\hline \multirow{3}{*}{$\mathbf{E}$} & \multirow{3}{*}{ TM DANOA } & Dectin-1, SR-E2 & Myeloid Cells, TAM & PRR, Anti-tumour immunity \\
\hline & & MR, MRC1, CD206, SR-E3 & $M \varphi, M \emptyset, ~ L S E C, ~ T A M$ & $\begin{array}{l}\text { Collagen clearance, PRR, Antigen } \\
\text { uptake, ALF/HCC biomarker }\end{array}$ \\
\hline & & ASGR1, HL-1, CLEC4H1, SR-E4 & Hepatocytes & Glycoprotein SR, Metastasis \\
\hline $\mathbf{F}$ & & SCARF-1, SRECI, SR-F1 & $M \varphi$, LSEC & $\begin{array}{c}\text { Apoptotic cell clearance, } \\
\mathrm{CD}^{*} \mathrm{~T}_{\text {eff }} \text { cell adhesion to LSEC, } \\
\text { PRR (HCV) }\end{array}$ \\
\hline G & & SR-PSOX, CXCL16, SR-G1 & $M \varphi, M \emptyset, D C$, LSEC & $\begin{array}{l}\text { CXCR6+ cell recruitment } \\
\left(T_{\text {eff, }} N K, N K T \text { cells }\right)\end{array}$ \\
\hline \multirow{2}{*}{ H } & & Stabilin-1, CLEVER-1, FEEL1, SR-H1 & $M \varphi, M \emptyset$, LSEC, TAM & oxLDL uptake, $T_{\text {res }}$ and $B$ cell TEM \\
\hline & & Stabilin-2, FEEL2, HARE, SR-H2 & LSEC & oxLDL uptake, Lymphocyte adhesion \\
\hline I & & CD163, CD163A, M130, SR-I1 & $M \varphi, M \emptyset$, TAM & $\begin{array}{l}\text { ALF biomarker, } \\
\text { Pro-tumour immunosuppression }\end{array}$ \\
\hline$\overline{\text { 뱅 }}$ & $\begin{array}{ll}\text { Cytoplasmic Tail } & \\
\text { Extracellular Domain } \\
\text { Transmembrane Domain }\end{array}$ & $\begin{array}{lll}\text { Coiled-coil } & \text { COSO } & \text { CD36 } \\
\text { Collagen } & \text { LAMP } & \text { LAMP } \\
\text { Cysteine-rich Domain } & 4 & \text { Mucin }\end{array}$ & $\begin{array}{l}\text { C-type Lectin Domain } \\
\text { EGF } \\
\text { EGF-like }\end{array}$ & $\begin{array}{l}\text { CXc) CXC-chemokine } \\
\text { Fasciculin } 1\end{array}$ \\
\hline
\end{tabular}

Fig. 1 Scavenger receptors implicated in liver homeostasis and pathogenesis, including receptor class, shared structural domains, liver cell expression, and functional role within the liver. Functions shown in green are considered protective and those shown in red are considered detrimental. Context-dependent functions are indicated in black. Figure created using biorender.com. ALF, acute liver failure; DC, dendritic cells; EC, endothelial cell; EGF, epidermal growth factor; HCC hepatocellular carcinoma; HCV, hepatitis C virus; HDL, high-density lipoprotein; HSC, hepatic stellate cell; LAMP, lysosome-associated membrane glycoprotein; LSEC, liver sinusoidal endothelial cell; $M \phi$, macrophage; $M_{\varnothing}$,

radiolabeled oxLDLs demonstrated a predominant role for LSEC stabilin-1 in the uptake of circulating mildly oxidized LDLs, while stabilin-2 was suggested to recognize heavily oxidized LDLs, which are often found within atherosclerotic

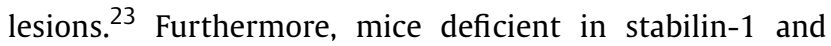
stabilin-2 have a reduced lifespan and develop glomerular and hepatic fibrosis. ${ }^{27}$ These studies highlight the homeostatic role for stabilin receptors, not just within the liver microenvironment, but at the systemic level.

LSECs have also been identified as the primary mechanism by which ECM components, such as collagen, are cleared from the circulation. Although both stabilin-1 and stabilin-2 have been implicated in the removal of profibrogenic circulating factors by LSEC, $^{27}$ the main receptor responsible for collagen clearance is thought to be mannose receptor (MR). ${ }^{28,29} \mathrm{MR}$ (also known as macrophage MR [MMR] and CD206) is a C-type lectin encoded by the MRC1 gene. Structurally, MR is composed of several domains within its large extracellular region, facilitating the binding of multiple ligands including lysosomal enzymes, ${ }^{30}$ tissue plasminogen activator, ${ }^{31}$ and mannose and $\mathrm{N}$-acetylglucosamine residues commonly found on the surface of pathogens. $^{32}$ In mice, MR was shown to play a nonredundant role in the endocytosis of denatured collagen that occurred in a calcium-independent manner, which is consistent with a binding site distinct from that of mannose or mannan. ${ }^{28}$ Furthermore, MR is important for maintenance of glycoprotein homeostasis, including clearance of advanced glycation end products. ${ }^{33}$ This is exemplified in MR knockout mice which have impaired clearance and elevated circulating levels of mannosylated glycoproteins. ${ }^{34}$

\section{Innate Immunity}

In addition to the homeostatic clearance of unwanted endogenous ligands, scavenger receptors are also well characterized in their binding and internalization of a highly diverse range of exogenous antigens expressed by numerous bacteria, viruses, and fungi. ${ }^{35}$ However, in spite of the extensive studies of the 
gut-liver axis as a key component of liver disease pathophysiology, ${ }^{36}$ the role of scavenger receptors in the innate immunity of the liver remains largely unexplored.

Scavenger receptors on Kupffer cells have been implicated in the "fast clearance" of bacteria from the circulation ${ }^{37}$; however, the specific scavenger receptor(s) involved remained undetermined by this study. Nevertheless, SR-AI in Kupffer cells has been shown to play a key role in the clearance of infection by the Gram-positive bacterium Listeria monocytogenes with SR-AI ${ }^{-1-}$ mice exhibiting impaired uptake and killing of $L$. monocytogenes and larger, more frequent hepatic granulomas, compared with wild-type (WT) control mice. ${ }^{38}$ $\mathrm{CD} 36$ in hepatic macrophages has been shown to play a role in the immune surveillance of nonbacterial pathogens, such as the fungal pathogen Cryptococcus neoformans. Significantly higher colony-forming units and significantly lower gene expression of inflammatory cytokines and chemokines were observed in livers of $\mathrm{CD} 36^{-1-}$ mice compared with WT mice in a murine model of $C$. neoformans infection. ${ }^{39}$ While several Kupffer cell-expressed scavenger receptors have been implicated in pattern recognition of several pathogens, they are not sufficient for effective systemic pathogen clearance, and so perhaps cannot be considered as phagocytic receptors per se. In contrast, complement receptor of the immunoglobulin family (CRIg), which is also highly expressed on Kupffer cells, is indispensable for the binding and clearance of complement component 3 (C3)opsonized particles ${ }^{40,41}$ and Gram-positive bacteria. ${ }^{42}$ Furthermore, whereas some C-type lectins such as dectin- 1 act as PRRs and endow the ability for phagocytosis, others, including MR, are not sufficient on their own to instill phagocytic capacity. ${ }^{43}$ Moreover, despite many scavenger receptors possessing short intracellular domains that often lack a signaling motif, several act as components of signalosomes in complex with toll-like receptors (TLRs), integrins, and/or tetraspanins, including CD9 and CD81. ${ }^{44,45}$ Indeed, scavenger receptors are known to form heterodimers with TLRs $^{44,46,47}$ and effectively boost the immune response to microbial antigens, compared with TLRs alone. ${ }^{48-52}$ Thus, the role of scavenger receptors in innate immunity must be considered in the wider context of other innate immune and phagocytic receptors.

In contrast, some intracellular pathogens are able to hijack hepatic macrophage-expressed scavenger receptors to aid in their infection of the host. CD36 appears to play an active role in the pathogenesis of Mycobacterium bovis Bacillus CalmetteGuérin infection, with $\mathrm{CD}_{3} 6^{-1-}$ mice exhibiting decreased mycobacterial burden and lower numbers of hepatic granulomas, and $\mathrm{CD}^{-1-}$ macrophages restricting mycobacterial growth in vitro. ${ }^{53}$ In addition, CD68 on Kupffer cells acts as a putative receptor for Plasmodium berghei sporozoites, ${ }^{54}$ playing a significant role in the hepatic invasion stage of the malaria-causing parasite's lifecycle.

Hepatic macrophages have long been considered the major player in the hepatic innate immunity, ${ }^{55}$ as they are largely responsible for the capture and clearance of pathogens from the bloodstream. ${ }^{37,42}$ However, LSECs are known to play a key role in the clearance of bacterial LPS, ${ }^{56}$ viruses, ${ }^{57}$ and viral particles ${ }^{58}$ from the bloodstream in vivo and have been shown to interact with several microbial antigens in vitro. ${ }^{59-61}$ In fact, a recent study has implicated LSEC-expressed stabilin-1 and stabilin-2 in the systemic clearance of LPS ${ }^{62}$; therefore, the role of LSEC-expressed scavenger receptors in hepatic innate immunity warrants future investigation.

\section{Immune Tolerance}

LSECs are known to be highly efficient antigen presenting cells, ${ }^{63,64}$ but rather than leading to $\mathrm{T}$ cell activation, they are skewed toward tolerance. ${ }^{65} \mathrm{MR}$ is a key player in promoting immune tolerance within the murine liver. Immune tolerance is critically important in maintaining hepatic homeostasis, due to the sustained exposure to low-level inflammatory agents from the gastrointestinal tract. For instance, uptake of oral antigens by MR has been shown to elicit tolerogenic responses following cross-presentation to $\mathrm{CD}^{+}{ }^{\mathrm{T}}$ cells. ${ }^{63,66}$ Furthermore, antigen presentation by LSEC is known to induce $\mathrm{CD}^{+} \mathrm{T}$ cell tolerance via upregulation of co-inhibitory molecule programmed cell death ligand-1. ${ }^{67}$ Notably, this has also been shown for tumor antigens, which led to tumor-specific $\mathrm{CD}^{+}$T cell tolerance. ${ }^{68,69}$ This suggests that under physiological conditions, LSEC antigen presentation is important for maintaining liver tolerance, but that this could prove detrimental in a neoplastic context.

\section{Scavenger Receptors in Liver Disease Pathology}

Acute Injury

Acute liver failure (ALF) is the fulminant loss of liver function, which arises due to severe hepatic insult, usually in the absence of pre-existing liver disease. Often occurring due to exposure to noxious stimuli (e.g. drugs, alcohol, or viruses), ALF is characterized by jaundice, elevated circulating aminotransferases, and in severe cases, coagulopathy and hepatic encephalopathy. The most common cause of ALF is acetaminophen overdose which is thought to account for more than $50 \%$ of cases and approximately $20 \%$ of liver transplant cases. ${ }^{70,71}$ Innate immune cell populations are key drivers of tissue damage in $\mathrm{ALF}^{72}$ yet despite their expression in these cell types and immunological functionalities being well documented, few studies have considered scavenger receptors in the context of ALF.

Some membranous scavenger receptors, such as CD163 and MR, are susceptible to proteolytic cleavage, leading to generation of soluble receptor forms which can retain some of their functional capacity. Often these are upregulated during inflammation and several have been characterized for their use as biomarkers of ALF. For instance, soluble CD163 (sCD163) is elevated in the circulation of ALF patients compared with healthy and cirrhotic patient controls, and is thought to represent increased intrahepatic macrophage activity. ${ }^{73-75}$ In addition, higher and prolonged levels of sCD163 correlated with markers of hepatic dysfunction (bilirubin, creatinine, aspartate transaminase, alanine aminotransferase) and incidence of patient fatality. ${ }^{74}$ Similarly, soluble MR (sMR) is increased in severe acetaminophen- 
induced liver injury. ${ }^{75} \mathrm{~A}$ recent study has also reported elevated SCD163 and sMR levels in patients with acute-onchronic liver failure, with both markers representing independent predictors of short- and long-term mortality. ${ }^{76,77}$

To date, very few functional studies of the role of scavenger receptors in acute liver injury have been undertaken. However, studies of SR-AI showed its upregulation in myeloid cells in both human acute hepatitis and murine models of acute liver injury and subsequently demonstrated its protective role in this context. ${ }^{78,79}$ Loss of SR-AI in transgenic mice was shown to significantly exacerbate liver damage in acute viral and hepatotoxin liver injury models, due to impairments in the anti-inflammatory activity of alternatively activated ("M2") macrophages and myeloid-derived suppressor cells. ${ }^{78,79}$

\section{Liver Inflammation}

The extravasation of immune cells from the systemic circulation to the liver occurs within the hepatic microvasculature, known as the sinusoids, which are lined by highly specialized LSECs. Immune cell recruitment to vascular endothelial cells occurs via the leukocyte adhesion cascade, a complex and sequential multistep process involving numerous adhesion molecules and chemokines. However, in the low-shear flow environment within the liver sinusoids, this process is somewhat distinct from that which occurs within more conventional vasculature. In most other organs of the body, the selectins, a small family of transmembrane $\mathrm{Ca}^{2+}$-dependent lectins, play a major role in the initial rolling and adhesion steps of the leukocyte cascade. However, in the low-shear flow environment of the liver, the initial selectin-mediated rolling steps are not required and, consequently, their expression in LSEC is minimal. This absence of selectins allows for a greater contribution by more atypical adhesion molecules to the recruitment of leukocytes to the liver. In addition, the latter stages of the leukocyte adhesion cascade in which immune cells cross the endothelial barrier, known as transendothelial migration (TEM), differ considerably in the liver when compared with other organs. TEM is a multistep receptor-mediated process which requires strict regulation by the endothelial layer to prevent vascular leakage. TEM can occur via two highly distinct pathways: (1) the paracellular route in which leukocytes transmigrate via the cellular junctions between adjacent cells or (2) the transcellular route where leukocytes pass through the body of endothelial cells. Our previous studies with primary human LSEC have demonstrated that a significant proportion of lymphocytes migrate via the transcellular route, rather than the paracellular route as observed in more conventional endothelia. Several groups have now demonstrated that scavenger receptors can act as atypical adhesion molecules. Others and we have shown that LSEC-expressed atypical adhesion molecules, which are key in the recruitment of leukocytes to the liver in the diseased state, include certain scavenger receptors.

\section{LSEC-Expressed Scavenger Receptors and Leukocyte Recruitment}

In addition to their primary scavenging function, several endothelial-expressed scavenger receptors have also been shown to exhibit a secondary functionality in which they act as atypical adhesion receptors in the leukocyte adhesion cascade. ${ }^{80}$ The majority of these have been characterized in LSEC and implicated in the recruitment of leukocytes to the liver. ${ }^{80}$

Perhaps the most well-studied of this subgroup of scavenger receptors is stabilin- $1 .{ }^{81}$ Stabilin-1 was first described as an atypical adhesion receptor in the trafficking of leukocytes across lymphatic vessels ${ }^{82,83}$ and the same group later described its role in the TEM of lymphocytes through both lymphatic and vascular endothelial cells. ${ }^{84,85}$ Our laboratory has previously characterized the expression of stabilin-1 in LSEC and explored its role in the TEM of lymphocytes to the liver. In our in vitro studies, which aim to mimic the physiological shear stress of the hepatic sinusoids, ${ }^{86}$ we showed that stabilin-1 specifically mediated the TEM of both regulatory $T$ cells $\left(T_{\text {reg }}\right.$ ) and B cells through primary human LSEC. ${ }^{87-89}$ Despite stabilin-1 being implicated in the transmigration of specific immune cell subsets in a range of contexts, the leukocyte-expressed ligand(s) remain elusive.

Like stabilin-1, stabilin-2 has also been shown to be expressed in LSEC $^{90-92}$ and mediates lymphocyte recruitment to primary human LSEC in vitro. ${ }^{91}$ However, despite significant sequence homology with stabilin-1, which as discussed above plays a role in the transmigration step of lymphocyte recruitment to LSEC, it has been suggested that stabilin-2 acts in the earlier stages of the leukocyte adhesion cascade, mediating the firm adhesion of lymphocytes. ${ }^{91}$ In addition, and again in contrast to stabilin-1, a lymphocyte-expressed ligand to stabilin-2, $\alpha_{M} \beta_{2}$ integrin, has been identified. ${ }^{91}$ Surprisingly, only one study to date has demonstrated the adhesive function of stabilin-2 and, given that other immune cell subsets, such as monocytes and neutrophils, also express $\alpha_{M} \beta_{2}$, future studies could aim to elucidate whether or not stabilin-2 also mediates the recruitment of myeloid cells to LSEC.

Scavenger receptor that binds phosphatidylserine and oxidized lipids (SR-PSOX) is the membrane-bound form of chemokine CXCL16 and, consequently, binds CXCR6 ${ }^{+}$leukocytes in a highly specific manner. ${ }^{93-96}$ SR-PSOX is thought to support leukocyte adhesion by triggering the conformational activation of immune-cell-expressed $\beta 1$ integrins and acts in the "arrest" stage of the leukocyte adhesion cascade. ${ }^{97}$ In the context of hepatic inflammation, SR-PSOX has been shown to interact with several proinflammatory intrahepatic immune cell subsets, such as effector T cells, ${ }^{97,98}$ natural killer (NK) cells $^{99,100}$ and NK T cells, ${ }^{101}$ all of which express CXCR6. In murine models of acute liver injury, pharmacological targeting of SR-PSOX with neutralizing antibodies and genetic deletion have been shown to significantly attenuate the intrahepatic inflammation and level of injury, ${ }^{102-104}$ thus highlighting its therapeutic potential. ${ }^{105}$

Another endothelial-expressed scavenger receptor which has previously been described in murine $\operatorname{LSEC}^{106}$ and, more recently, in human $\mathrm{LSEC}^{60}$ is SCARF1. By utilizing physiological flow-based adhesion assays with immobilized recombinant SCARF1 and antibody-inhibited or siRNA-silenced primary human LSEC, SCARF-1 was shown to mediate the adhesion of $\mathrm{CD} 4^{+} \mathrm{T}$ cells to $\mathrm{LSEC}{ }^{60}$ In addition, the role of SCARF1 was $\mathrm{CD}^{+}{ }^{+}$subset-specific with preferential binding 
to proinflammatory "effector" $\mathrm{CD} 4^{+} \mathrm{T}$ cells, rather than their regulatory $\mathrm{CD} 4^{+} \mathrm{CD} 25^{+}$counterparts $\left(\mathrm{T}_{\text {reg }}\right){ }^{107}$ These studies ruled out the possibility of a homophilic interaction, as $\mathrm{CD} 4^{+}$ $\mathrm{T}$ cells did not express SCARF1, but the ligand is yet to be identified.

The role of scavenger receptors as atypical adhesion molecules is interesting to consider in the context of recruitment via conventional adhesion molecules such as intercellular adhesion molecule 1 (ICAM-1) and vascular cell adhesion molecule 1 (VCAM-1). Conventional adhesion molecules have a significant role to play in regulating the immune microenvironment in liver diseases. ${ }^{108,109}$ Recent work has confirmed this in models of fatty liver disease, where VCAM-1 and ICAM-1 expressed on LSEC have been implicated in regulating proinflammatory monocyte recruitment. ${ }^{110}$ It is therefore possible that scavenger receptors may amplify or modify the roles of conventional adhesion molecules. For example, in human in vitro models, $\mathrm{T}_{\text {reg }}$ TEM was inhibited by $50 \%$ by ICAM- 1 blockade but with the combination of stabilin-1 blockade this was increased to $80 \%$ inhibition. ${ }^{87}$

\section{Viral Hepatitis}

Viral hepatitis is a global health problem, accounting for over a million deaths worldwide each year, ${ }^{111}$ with a large proportion of those deaths attributed to hepatitis $\mathrm{C}$ virus (HCV). ${ }^{112}$ Hepatic inflammation resulting from HCV can manifest from acute or chronic infection and is a major cause of liver cirrhosis and HCC. ${ }^{113} \mathrm{HCV}$ is a hepatotropic RNA virus and direct infection of hepatocytes is largely responsible for the resultant inflammatory disease. ${ }^{114-116}$ While patients with HCV can now undergo highly effective therapy to eradicate the virus in symptomatic disease, there is still no preventative vaccine available and often infection leads to asymptomatic liver disease that can present at advanced stages with cirrhosis and HCC.

In normal physiology, scavenger receptor class B member 1 (SCARB1) on hepatocytes acts as receptor for high-density lipoproteins and plays a key role in cholesterol homeostasis. ${ }^{117}$ However, in the context of viral hepatitis, SCARB1 is one of four receptors known to act as a HCV entry factor in human hepatocytes ${ }^{118-121}$ and binds to HCV via its envelope glycoprotein E2. ${ }^{122}$ Consequently, SCARB1 is strongly implicated in the pathogenesis of viral hepatitis and this is emphasized by the fact that patients with genetic variants of SCARB1 exhibit altered viral load ${ }^{123}$ and virological responses. ${ }^{124,125}$ Nevertheless, therapeutic targeting of SCARB1 with an antagonist in early-phase clinical trials demonstrated relatively low efficacy in HCV patients, suggesting a certain level of redundancy in its role. ${ }^{126,127}$ In addition, and consistent with scavenger receptors being considered PRRs, one study has implicated both SR-AI and SCARF1 in the uptake and cross-presentation of HCV nonstructural (NS)3 protein by human myeloid cells (dendritic cells [DCs] and monocytes). ${ }^{49}$

\section{Fibrosis}

Hepatic fibrosis is the process in which the excessive accumulation of ECM proteins, such as collagens, fibronectin, and elastin, effectively replaces the parenchymal tissues of the liver, thus significantly distorting its histology and vastly reducing its functionality. ${ }^{128}$ The major source of these ECM proteins is the HSC, a liver-resident pericyte which, when chronically activated by paracrine inflammatory signals from the diseased liver microenvironment, transdifferentiates toward a profibrogenic myofibroblast phenotype. ${ }^{129}$ It has previously been suggested that direct HSC uptake of oxLDLs via CD36 and LOX-1 contributes to their activation and production of ECM proteins. ${ }^{130,131}$ In addition, one study has suggested that Class A scavenger receptors may play a role in HSC activation in response to apoptotic bodies derived from HCV-infected hepatocytes. ${ }^{132}$

Stabilin-1 expression is absent from HSCs; however, its presence/absence on other hepatic cell types is still able to indirectly influence HSC activation and hepatic fibrosis in vivo. Stabilin-1-deficient mice are phenotypically normal and exhibit a comparable lifespan to WT littermates ${ }^{27}$; however, histological analyses of their livers demonstrated the presence of a mild, peri-sinusoidal deposition of collagen fibers. ${ }^{17,27}$ This was indicative of a role for stabilin-1 in hepatic fibrogenesis and subsequent studies in the context of chronic liver injury further highlighted this. Utilizing a chronic carbon tetrachloride $\left(\mathrm{CCl}_{4}\right)$ model of bridging hepatic fibrosis with a resolution phase, these studies demonstrated that a lack of stabilin- 1 exacerbated the level of fibrosis and delayed its resolution. ${ }^{17}$ In uninjured liver tissues, stabilin-1 expression is limited to endothelial cells ${ }^{87}$; however, in the context of inflammatory disease, a sub-population of stabilin- $1^{+}$macrophages was also evident. ${ }^{17}$ Cell-specific knockout mice (ENDO stab-1 ${ }^{-1-}$ and MACRO stab- $1^{-1-}$ ) were used to confirm that stabilin-1 in macrophages was the key contributor to the limitation of fibrosis in chronic injury. Additionally, adoptive transfer of stabilin-1-expressing myeloid cells, derived from bone marrow of WT mice, into MACRO stab-1 $1^{-1-}$ mice was able to rescue the phenotype. Mechanistically, the scavenging of oxLDLs, and more specifically malondialdehyde (MDA)-LDLs, by macrophageexpressed stabilin-1 resulted in the suppression of CCL3 production. CCL3 is a proinflammatory and profibrotic chemokine known to influence fibroblast phenotype and its increased expression from macrophages in the livers of stab$1^{-/-}$and MACRO stab- $1^{-/-}$mice led to increased fibrosis and delayed resolution. ${ }^{17}$

\section{Steatosis and NASH}

NAFLD is characterized by the chronic and excessive accumulation of lipids within the liver and is the precursor to a progressive and inflammatory form of the disease, NASH. ${ }^{133}$ Given the global obesity crisis, NASH is increasing in prevalence and causes an incredible disease burden and economic impact worldwide. ${ }^{133}$ NASH is classically characterized by steatosis, inflammation, and fibrosis, and a recent study has implicated SR-AI in the progression of NAFLD to NASH. ${ }^{134}$ Govaere et al showed that SR-AI expression strongly correlated with the degree of steatosis and inflammation in a large cohort of NAFLD patients and, by utilizing a combination of murine models, novel ex vivo human liver 
tissue models, and in vitro experiments, they demonstrated a direct role for hepatic macrophage-expressed SR-AI in the uptake of free fatty acids, subsequently driving them toward a proinflammatory phenotype. ${ }^{134}$ SCARB1 has also been demonstrated to be significantly upregulated in both murine and human NAFLD ${ }^{135}$ and mice deficient in SCARB1 were recently shown to have significantly reduced levels of hepatic triglycerides in comparison to WT mice in a murine model of NAFLD. ${ }^{136}$

However, the best studied scavenger receptor in context of lipid metabolism, steatosis, and NAFLD/NASH is CD36. ${ }^{137}$ CD36 is widely expressed in the liver and has been studied in a range of hepatic cell types, including hepatocytes, ${ }^{138,139}$ HSC, ${ }^{130}$ LSEC, ${ }^{140}$ Kupffer cells, ${ }^{141,142}$ and even intrahepatic lymphocytes. ${ }^{143} \mathrm{CD} 36$ has consistently been shown to be significantly upregulated in NAFLD and NASH liver tissues in comparison to normal liver control tissues ${ }^{144-146}$; however, the full significance of its role in NAFLD/NASH pathogenesis is still to be realized. ${ }^{137}$ Nevertheless, overexpression of CD36 in murine livers significantly increased accumulation of hepatic triglycerides and cholesteryl esters in a model of diet-induced obesity ${ }^{147}$ and hepatocyte-specific deletion of CD36 protected mice from steatosis and improved insulin sensitivity in a high-fat diet liver injury model. ${ }^{148}$ In addition, the soluble form of $\mathrm{CD} 36$ may present as a biomarker for steatosis in NAFLD. ${ }^{149,150}$

\section{Scavenger Receptors in HCC}

\section{Tumor Endothelial Cell Expression of Scavenger Receptors}

Several scavenger receptors have previously been implicated in the pathogenesis of a range of cancers ${ }^{13}$ and HCC is no exception to this. In general, scavenger receptors are considered to be largely anti-inflammatory and, therefore, potentially pro-tumorigenic in nature; however, a seminal study demonstrated a key role for SR-PSOX/CXCL16 in LSEC-mediated recruitment of antitumoral NKT cells. ${ }^{151}$ The results of this study showed that disruption of the commensal gut microbiota and accumulation of primary bile acids in the liver upregulated the expression of SR-PSOX/CXCL16 on LSEC, mediating the recruitment of CXCR6 ${ }^{+}$NKT cells which in turn effectively limited tumor formation and metastasis in mice. ${ }^{151}$ More recently, studies on the expression of SCARF1 in tumor endothelial cells in human HCC tissues demonstrated a correlation with lower tumor aggressiveness, better survival, and increased inflammation. ${ }^{107}$ From a functional perspective, the data suggested that SCARF1 potentially plays a role in the selective recruitment of proinflammatory "effector" $\mathrm{CD} 4^{+} \mathrm{T}$ cells which could initiate an antitumoral immune response. ${ }^{107}$

Stabilin-1, which has been shown to recruit $T_{\text {reg }}$, is also expressed in tumor endothelial cells in human HCC tissues. ${ }^{87}$ This suggests that the presence of stabilin- 1 in HCC could be immunosuppressive and protumorigenic, a hypothesis which is supported by murine tumor models. In these studies, the genetic and therapeutic targeting (via antibody blockade) of stabilin-1 resulted in smaller primary and metastatic tumors and diminished numbers of immunosuppressive leukocytes, such as $\mathrm{T}_{\text {reg. }}{ }^{152}$

\section{Scavenger Receptors in TAMs}

In addition to transformed cancer cells, the tumor microenvironment (TME) in HCC is composed of several other stromal components, including immunosuppressive tumor-associated macrophages (TAMs) which drive tumor growth, survival, and metastasis. ${ }^{153,154}$ These TAMs are highly plastic and thought to originate from circulating monocytes, whose phenotype is shaped by the environmental cues found within the TME. The "M2" or "alternative activation" state of TAMs is well documented, and has been shown to promote an immunosuppressive phenotype, which can facilitate tumor immune evasion in HCC. ${ }^{155,156}$

MR is considered a definitive marker of the "M2" TAM population $^{157}$ and has, unsurprisingly, been shown to be expressed in TAMs within HCC tumor tissues, with their presence being highly indicative of poor patient prognosis. ${ }^{158,159}$ However, the direct contribution of MR to the TME in the context of HCC remains unexplored to date. Nevertheless, MR is known to directly bind tumoral mucins and this is speculated to drive immunosuppression by interleukin (IL)10-mediated $\mathrm{T}_{\text {reg }}$ induction and downregulation of IL-12. ${ }^{160,161}$ Furthermore, targeting of TAM-expressed MR with a synthetic peptide analogue in murine xenograft models resulted in M2 macrophage reprogramming to an antitumor "M1" phenotype, as well as inducing apoptosis of the M2 TAM population. ${ }^{162}$ These studies demonstrate the potential for targeting TAM-expressed MR in the context of HCC and future studies should explore this possibility.

Similar to MR, CD163 is also a marker of immunosuppressive TAMs, which has been demonstrated in multiple cancers. ${ }^{163-166}$ CD163 is the prototypic member of the class I family of scavenger receptors which bind and clear hemoglobin-haptoglobin complexes. ${ }^{167-169}$ As such, this receptor prevents hemoglobin-induced inflammation under physiological conditions, but can also stimulate protumorigenic M2 polarization in a pathophysiological context. Specifically, hemoglobin release into the circulation, arising from pathological intravascular hemolysis within the tumor, can activate stress-responsive enzyme heme oxygenase $1 .^{169}$ This enzyme has been implicated in M2 polarization and IL-10 production. ${ }^{170,171}$ Moreover, CD163 is involved in the sequestration and subsequent inactivation of proinflammatory tumor necrosis factor-like weak inducer of apoptosis (TWEAK), further contributing to the TAM immunosuppressive phenotype. ${ }^{172}$ In support of this, enhanced peritumoral CD163 has been shown to correlate with poor prognosis and higher incidence of vascular invasion in HCC patients. ${ }^{154,173}$

Another scavenger receptor highly expressed in TAMs is stabilin-1. ${ }^{174}$ TAM stabilin-1 has been shown to scavenge antitumor factor, secreted protein, acidic and rich in cysteine (SPARC), which promoted tumor progression in an in vivo model of breast cancer. ${ }^{174}$ Studies in mice have highlighted that genetic stabilin-1 deficiency leads to reduced intratumoral "M2" macrophages and FoxP3 ${ }^{+} \mathrm{T}_{\text {reg, demonstrating }}$ a role for stabilin-1 in shaping the immunosuppressive 
TME. ${ }^{152}$ Importantly, macrophage-specific deletion of the stabilin-1 gene reduces tumor growth and metastatic spread, and anti-stabilin-1 antibody treatment of WT mice inhibits tumor progression. ${ }^{152}$ Furthermore, stabilin-1 levels positively correlate with resistance to immune checkpoint therapies and $\mathrm{T}$ cell dysfunction in numerous cancer types. ${ }^{175}$ Recently, a phase I/II first-in-man clinical trial in advanced solid tumor cancer patients including HCC demonstrated that the targeting of stabilin-1 with a function blocking antibody led to a significant phenotype switch in circulating monocytes. Interestingly, early results in patients where biopsies were undertaken did show a reduction of antiinflammatory intratumoral stabilin $-1^{+}$macrophages and an increase in proinflammatory/adaptive immune cell subsets in selected patients. ${ }^{176}$ This trial is ongoing and overall therapeutic efficacy is awaited, yet the data are consistent with the detrimental effects of TAM scavenger receptors and their role in driving an immunosuppressive TME, and also highlight therapeutic potential for their targeting within the context of HCC.

Conversely, scavenger receptors found on TAMs can also drive protective antitumor responses. For instance, dectin-1, a C-type lectin belonging to the class E family of scavenger receptors, can stimulate both innate and adaptive arms of the immune system to enhance immune-mediated tumor cell killing. Dectin- 1 is the primary $\beta$-glucan receptor on myeloid DCs, macrophages, monocytes, and B cells and is upregulated in both DCs and TAMs within murine HCC tumors, when compared with normal liver tissues. ${ }^{177}$ In addition, treatment of TAMs with $\beta$-glucan has been shown to convert "M2" polarized macrophages into an "M1-like" phenotype in a dectin-1-dependent manner. ${ }^{178}$ Moreover, oral $\beta$-glucan treatment enhanced effector $\mathrm{T}$ cell activation and delayed tumor growth in mice. ${ }^{178}$ Furthermore, recognition of tumor cells by DC- and macrophage-derived dectin-1 drives tumoricidal activity of NK cells and induces inflammatory cytokine production. ${ }^{179,180}$ Consistent with this, dectin-1-deficient mice display exacerbated tumor growth in a murine model of HCC. ${ }^{177}$ Thus, TAM scavenger receptors have a pleiotropic role in mediating the TME.

\section{Scavenger Receptors in Metastasis of HCC}

The majority of scavenger receptors within the context of HCC are expressed in tumor-associated stromal and immune cell populations, such as tumor endothelia and TAMs; however, one scavenger receptor known to be expressed directly by tumor cells in HCC is asialoglycoprotein receptor 1 (ASGR1). ${ }^{181,182}$ ASGR1 is a hepatic C-type lectin receptor which is constitutively expressed in hepatocytes and its primary function is to mediate the endocytosis of serum glycoproteins, particularly those containing galactose or $\mathrm{N}$-acetylgalactosamine moieties. ${ }^{183,184}$ ASGR1 expression was found to be downregulated in HCC tumors when compared with matched nontumorous tissues; however, higher intratumoral expression of ASGR1 in HCC was shown to be associated with better patient survival. ${ }^{185}$ The same study also demonstrated that ASGR1 works in conjunction with longevity assurance homolog 2 of yeast LAG1 (LASS2) to inhibit vacuolar $\mathrm{H}^{+}$-ATPase (V-ATPase) activity in HCC tumor cells, effectively suppressing cell migration and invasion (i.e., metastasis).

Similarly, the intratumoral expression of another scavenger receptor, MARCO, has been shown to be associated with better patient prognosis ${ }^{186}$ and its overexpression in hepatoma cell lines appeared to inhibit their migration and invasive properties, inducing apoptosis both in vitro and in vivo. ${ }^{186}$ However, unlike ASGR1, which seems to be exclusively expressed on hepatocytes and HCC tumor cells, the expression of MARCO is also well known to be largely expressed by hepatic macrophages ${ }^{187,188}$; therefore, more in-depth studies are required.

\section{Clinical Translation and Future Perspectives}

Over the last few years, scavenger receptors have increasingly been considered viable clinical targets ${ }^{80,189-191}$; however, their full translational potential is yet to be realized as clinical trials have been limited in this field. In - Fig. 2, we summarize the translational progress in the study of scavenger receptors in liver disease, with two early-phase clinical trials active/completed to date. The first of these targeted scavenger receptor SCARB-1 in HCV cell entry in the context of liver transplantation ${ }^{127}$ and the second is an early-phase clinical trial currently underway, targeting the scavenger receptor stabilin-1 on TAMs in solid tumors, including HCC. ${ }^{176}$ In addition, scavenger receptors have also been explored as biomarkers of disease states, and here we highlight their potential as biomarkers in different etiologies of liver disease (-Fig. 2 ).

Nevertheless, there are still several questions that need to be explored before we can fully understand the contribution of scavenger receptors to liver disease and neoplasia, their therapeutic potential, and their practicality as disease biomarkers. While scavenger receptors share overlapping ligand recognition, the cellular responses can be divergent. ${ }^{9}$ Better understanding is therefore needed of the cell signaling that takes place when specific scavenger receptors bind to their ligands to design therapies/small-molecule inhibitors that can take advantage of scavenger receptor biology. Detailed understanding is also needed of receptor dynamics, shedding, and recycling in homeostasis and how this may differ in disease settings, which will provide crucial information for pharmacokinetics and pharmacodynamics of drug design. With regard to liver disease, targeting of the complex tissue microenvironment remains a challenge in the setting of chronic hepatitis and neoplasia. Further studies are required to understand the contributions of scavenger receptors to persistent inflammation which drives liver fibrosis, and in contrast, the suppression of hepatic immune responses that permit the growth of tumors in the case of HCC and cholangiocarcinoma. One emerging technology which could aid in this process is single-cell RNA-sequencing (scRNA-seq). Recent scRNA-seq studies have highlighted tissue-resident and infiltrating immune cell populations, as well as inflammation- and cancer-associated hepatic cell subsets in human and mouse liver tissues. ${ }^{192-194}$ Data generated from this technology could be utilized to examine the specific cell 


\begin{tabular}{|c|c|c|c|}
\hline \multirow{2}{*}{ Scavenger Receptor } & Translational Stage & \multicolumn{2}{|c|}{ Biomarker? } \\
\hline & Clinical Trials & Serum & Tissue \\
\hline SR-Al & 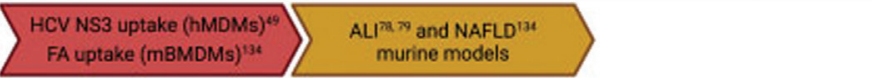 & & $\begin{array}{l}\text { ALI, } \\
\text { NASH }\end{array}$ \\
\hline MARCO & 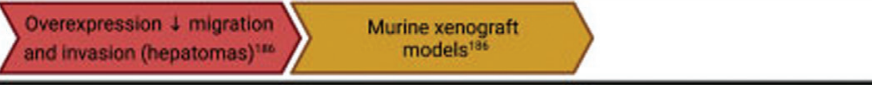 & & $\begin{array}{c}\mathrm{HCC}, \\
\text { Metastasis }\end{array}$ \\
\hline SCARB1 & 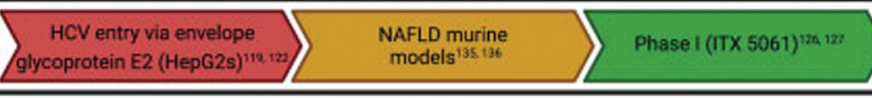 & & $\begin{array}{l}\text { NAFLD, } \\
\text { HCV } \\
\text { Therapy }\end{array}$ \\
\hline CD36 & $\left.\sum \begin{array}{c}\text { OxLDL uptake by human } \\
\text { and rat HSCs's }\end{array}\right\rangle \begin{array}{c}\begin{array}{c}\text { NAFLD murine } \\
\text { models }\end{array} \\
\text { tat ins }\end{array}$ & NAFLD & \\
\hline Dectin-1 & 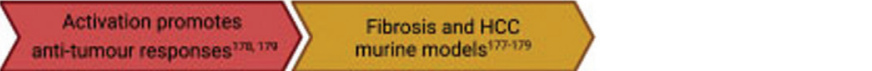 & & $\begin{array}{l}\text { Fibrosis, } \\
\text { HCC }\end{array}$ \\
\hline MR & $\left.\begin{array}{c}\text { CEA uptake promotes } \mathrm{CD}^{\circ} \\
\text { T cell tolerance (mLSEC) }\end{array}\right\rangle \begin{array}{c}\text { Murine exenograft } \\
\text { models }\end{array}$ & ALF & HCC TAM \\
\hline ASGR1 & \begin{tabular}{c|c}
$\left.\begin{array}{l}\text { Prevents migration and } \\
\text { invasion (hepatomas) }\end{array}\right\rangle \begin{array}{c}\text { Murine xenograft } \\
\text { models } s^{135}\end{array}$ \\
\end{tabular} & & Metastasis \\
\hline SCARF1 & 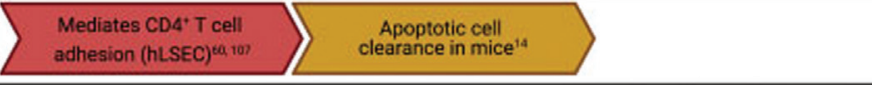 & & $\uparrow$ Cirrhosis, \\
\hline SR-PSOX & 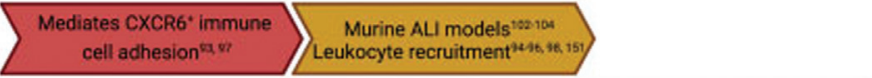 & $\begin{array}{l}\text { Liver } \\
\text { Injury }\end{array}$ & \\
\hline Stabilin-1 & 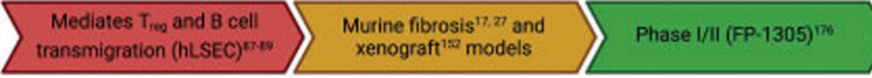 & & \\
\hline Stabilin-2 & $\left.\sum \begin{array}{c}\text { Mediates lymphocyte firm } \\
\text { adhesion (hLSEC) }\end{array}\right\rangle \begin{array}{c}\text { Murine fibrosis } \\
\text { modeles }\end{array}$ & & \\
\hline CD163 & 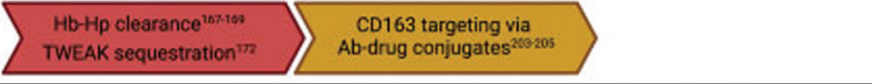 & ALF & HCC TAM \\
\hline
\end{tabular}

Fig. 2 Scavenger receptors represent valid therapeutic targets and are often valuable for use as biomarkers of liver disease, either in their soluble form in the serum or their cellular form within the tissues. This table summarizes the translational stage of each scavenger receptor, including in vitro and in vivo preclinical models and ongoing or completed clinical trials. Figure created using biorender.com. ALF, acute liver failure; ALI, acute liver injury; CEA, carcinoembryonic antigen; FA, fatty acid; Hb-Hp, hemoglobin-haptoglobin complex; HCC, hepatocellular carcinoma; HCV, hepatitis C virus; hLSEC, human liver sinusoidal endothelial cells; hMDMs, human monocyte-derived macrophages; HSC, hepatic stellate cells; mBMDMs, murine bone marrow-derived macrophages; mLSEC, murine liver sinusoidal endothelial cells; NAFLD, nonalcoholic fatty liver disease; NASH, nonalcoholic steatohepatitis; NS3, nonstructural 3 protein; oxLDL, oxidized low-density lipoprotein; TAM, tumor-associated macrophage; $\mathrm{T}_{\text {reg }}$, regulatory T cells; TWEAK, tumor necrosis factor-like weak inducer of apoptosis.

subtype expressers of scavenger receptors and better inform us of their role within the liver and TMEs.

In addition to directly targeting scavenger receptors for treatment of liver diseases, scavenger receptors may also be useful in the delivery of emerging liver-specific and even cellspecific therapeutics, such as nanoparticles, oligonucleotides, and antibody-drug conjugates. Nanoparticles are small $(<500 \mathrm{~nm})$ quasi-spherical, hollow particles that can be loaded with a range of existing pharmaceutical drugs and utilized to circumvent problems such as solubility and off-target toxicity. ${ }^{195}$ Due to the endocytic nature of liverresident cells, drug-laden nanoparticles passively accumulate within the liver, ${ }^{195,196}$ and are known to be internalized by scavenger receptors. ${ }^{197}$ Recently, nanoparticle uptake experiments in zebrafish (Danio rerio) have implicated stabilin-1 and stabilin- 2 as key receptors in their clearance by liver endothelial cells and have been utilized to provide proof-of-concept data in the design of targeted and cellspecific drug delivery systems. ${ }^{198,199}$ Stabilin-1 and stabilin2 are also considered to be key molecules in the delivery of oligonucleotide therapeutics. ${ }^{200}$ Oligonucleotide therapeutics, such as antisense oligonucleotides, are increasingly being recognized in translational science as an effective therapeutic tool and a number of them have been approved for use in the clinic to treat a range of diseases. ${ }^{201}$ Scavenger receptors, such as stabilin-1, stabilin-2, and ASGR1, can be specifically targeted by direct modifications to the oligonucleotides themselves, ${ }^{200,202}$ and SR-AI and SCARF1 have been utilized in the delivery of oligonucleotides via viral vectors. ${ }^{106}$ Another promising emerging technology in which scavenger receptors have been effectively exploited in preclinical models is antibody-drug conjugation. Anti-CD163 
antibody-drug conjugates allow highly efficient delivery of drugs to $\mathrm{CD}_{163}{ }^{+}$macrophages, for example, antibody-conjugated dexamethasone displays a high affinity for CD163 and showed a 50 -fold more potent anti-inflammatory response than nonconjugated dexamethasone in a rat model of endotoxemia. ${ }^{203}$ Furthermore, CD163 antibody-conjugated dexamethasone specifically targeted Kupffer cells and significantly reduced steatohepatitis and fibrosis in a rat model of NAFLD. ${ }^{204}$ In addition, this therapeutic strategy may also be valuable in the context of HCC, since CD163 is highly expressed by TAMs, which are indicative of poor patient prognosis. ${ }^{154,173}$ Indeed, doxorubicin-containing antiCD163 liposomes have been shown to reduce tumor growth and enhance monocyte and $\mathrm{CD} 4^{+} / \mathrm{CD}^{+} \mathrm{T}$ cell infiltration via depletion of immunosuppressive TAMs. ${ }^{205}$

Future translational work will hopefully take advantage of the potential of scavenger receptors as biomarkers, to aid in stratifying patients, and as direct therapeutic targets and/or delivery molecules. This could facilitate the design of personalized therapies that target specific scavenger receptors depending on disease stage or cancer risk.

\section{Conclusions}

PRRs play a crucial role in the initial response to foreign pathogens and are a vital link between the innate and adaptive immune response. The literature often highlights the role of TLRs and the inflammasome, but gathering evidence demonstrates that scavenger receptors are also important players in this process. Like the TLR family and inflammasome, they are highly evolutionarily-conserved and recognize a wide array of ligands. The belief that they demonstrate a high level of redundancy is also being brought into question by the use of transgenic murine models, especially in the context of tissue injury.

The liver has a critical role in maintaining homeostasis from a metabolic and immune point of view. Its contribution to tolerance is now well recognized and it can also be the victim of a range of insults which if chronic can lead to a maladaptive wound healing response. The increased expression of scavenger receptors within the hepatic microenvironment contributes to both the metabolic and immune functions of the liver. As discussed, scavenger receptors are a highly diverse superfamily of receptors and, as a result, it is unsurprising that they have been found to play a multitude of roles in the pathogenesis of acute liver injury, chronic liver disease, and HCC (-Fig. 3). While these receptors can be expressed on a range of cell types, they are highly expressed on macrophages and endothelial cells. Studies in the context of liver inflammation and fibrosis have demonstrated that scavenger receptor function contributes to leukocyte subset trafficking across endothelium ${ }^{60,87}$ and macrophage polarization. ${ }^{17,79}$ Given the inflammatory cell infiltration that characterizes all liver diseases and the well-recognized

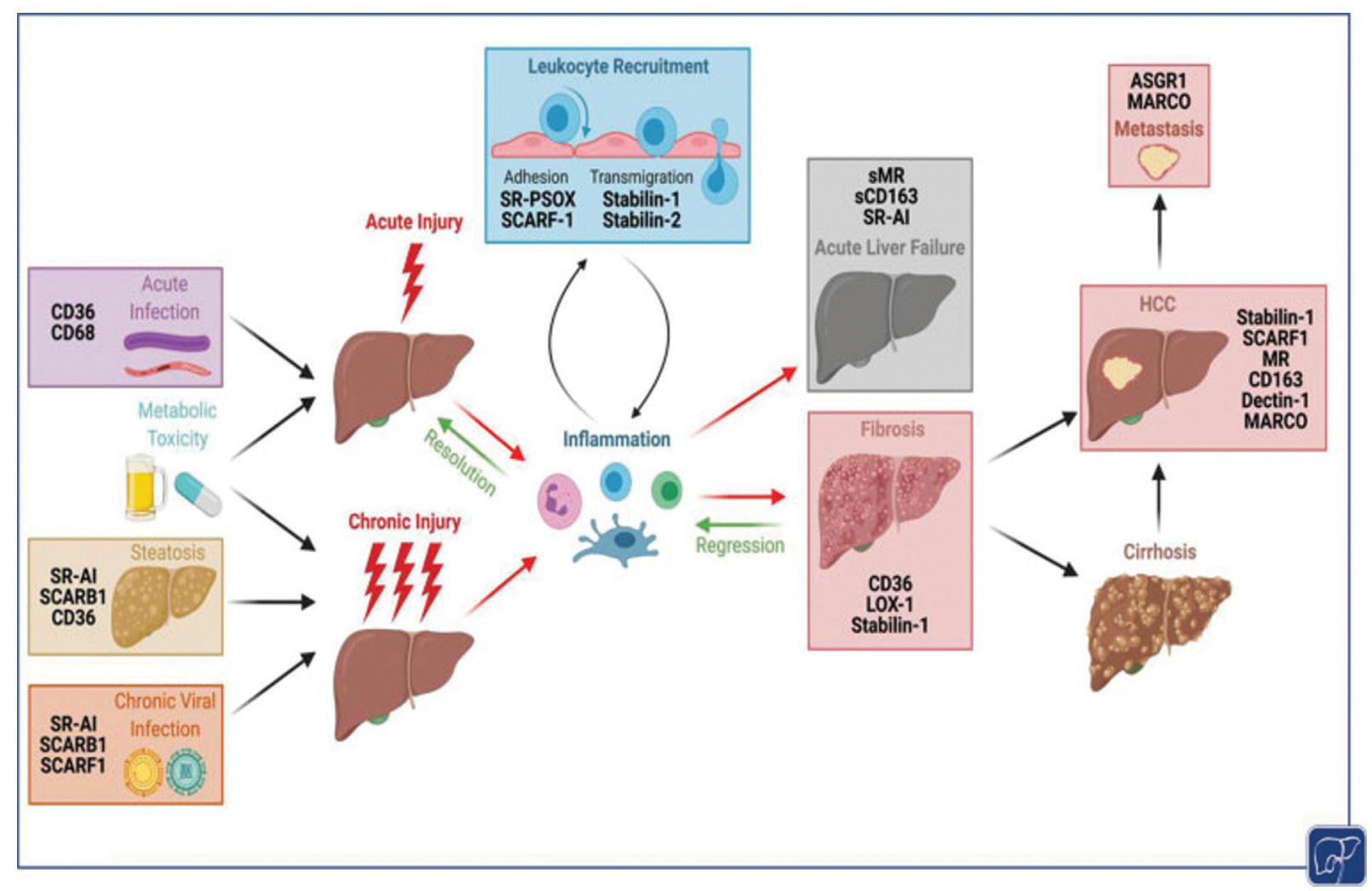

Fig. 3 Scavenger receptors have widespread and pleiotropic roles in liver pathophysiology. Acute or chronic liver injury causes inflammation, which if unresolved, can progress to fibrosis or acute liver failure, respectively. Inflammation is underpinned by leukocyte recruitment across the sinusoidal endothelium, and several scavenger receptors have been implicated in adhesion or transmigration steps of the leukocyte adhesion cascade. Although early fibrosis can regress, if noxious stimulus is not removed and liver injury persists, fibrosis will progress to cirrhosis and/or hepatocellular carcinoma (HCC). Figure created using biorender.com. 
role of macrophages in regulating liver fibrosis, ${ }^{206}$ these scavenger receptor properties should impact on the immune and stromal microenvironment of human liver disease and support their potential as therapeutic targets for fibrosis and cancer within the liver.

In this review, we have covered some of the pathways that are regulated by scavenger receptors in the tissue microenvironment of chronic liver injury and carcinogenesis. The potential of scavenger receptors to positively influence the liver microenvironment in the disease setting and their potential to act as therapeutic targets are only just starting to be realized, with a small number of early-phase clinical trials having been undertaken to date. However, we predict that this unique family of receptors, which often have a cell-specific expression, could be highly attractive in regulating distinct inflammatory pathways and in targeting specific sites of disease.

\section{Main Concepts and Learning Points}

- Inflammation is a key pathological component of acute and chronic liver injuries, cirrhosis, and hepatocellular carcinoma (HCC); however, the molecules and pathways involved in hepatic inflammation are yet to be fully elucidated.

- Scavenger receptors are a highly diverse superfamily of receptors which play an important role in homeostasis, but are also associated with the pathophysiology of several inflammatory diseases.

- Scavenger receptors are highly expressed within the liver, particularly in hepatic macrophages and liver sinusoidal endothelial cells (LSECS), and regulate discrete immune pathways in response to hepatic infection and sterile injury.

- Despite sharing the recognition of several ligands, scavenger receptors have been shown to play nonredundant roles in shaping the stromal response in preclinical models of liver injury.

- Developing agents that target scavenger receptors could be a promising approach in treating fibrosis and carcinogenesis within the hepatic microenvironment.

\section{Funding}

Funding received from Cancer Research UK under the ID: C53575/A29959; funding received from the Wellcome Trust under MIDAS Mechanisms of Inflammatory Disease.

\section{Conflict of Interest}

Dr. Shishir Shetty declares that he received consultation fees from Faron Pharmaceuticals, and the payment was managed by his institution, University of Brimingham, Birmingham, United Kingdom.

\section{References}

1 Global World Health Organisation. Global Health Estimates 2020: deaths by cause, age, sex, by country and by region, 2000-2019. Published 2020. Accessed April 27, 2021 at: https://www.who.int/data/gho/data/themes/mortality-and-globalhealth-estimates/ghe-leading-causes-of-death

2 Ibrahim SH, Hirsova P, Gores GJ. Non-alcoholic steatohepatitis pathogenesis: sublethal hepatocyte injury as a driver of liver inflammation. Gut 2018;67(05):963-972

3 Hirschfield GM, Karlsen TH, Lindor KD, Adams DH. Primary sclerosing cholangitis. Lancet 2013;382(9904):1587-1599

4 Tsuchida T, Friedman SL. Mechanisms of hepatic stellate cell activation. Nat Rev Gastroenterol Hepatol 2017;14(07):397-411

5 British Liver Trust. The alarming impact of liver disease in the UK. Published 2019. Updated June 2019. Accessed July 13, 2021 at: https://britishlivertrust.org.uk/wp-content/uploads/The-alarmingimpact-of-liver-disease-FINAL-June-2019.pdf

6 Pimpin L, Cortez-Pinto H, Negro F, et al; EASL HEPAHEALTH Steering Committee. Burden of liver disease in Europe: Epidemiology and analysis of risk factors to identify prevention policies. J Hepatol 2018;69(03):718-735

7 O'Rourke JM, Sagar VM, Shah T, Shetty S. Carcinogenesis on the background of liver fibrosis: implications for the management of hepatocellular cancer. World J Gastroenterol 2018;24(39): 4436-4447

8 Bray F, Ferlay J, Soerjomataram I, Siegel RL, Torre LA, Jemal A. Global cancer statistics 2018: GLOBOCAN estimates of incidence and mortality worldwide for 36 cancers in 185 countries. CA Cancer J Clin 2018;68(06):394-424

9 Canton J, Neculai D, Grinstein S. Scavenger receptors in homeostasis and immunity. Nat Rev Immunol 2013;13(09):621-634

10 Goldstein JL, Ho YK, Basu SK, Brown MS. Binding site on macrophages that mediates uptake and degradation of acetylated low density lipoprotein, producing massive cholesterol deposition. Proc Natl Acad Sci U S A 1979;76(01):333-337

11 PrabhuDas MR, Baldwin CL, Bollyky PL, et al. A consensus definitive classification of scavenger receptors and their roles in health and disease. J Immunol 2017;198(10):3775-3789

12 Krieger M. The other side of scavenger receptors: pattern recognition for host defense. Curr Opin Lipidol 1997;8(05):275-280

13 Yu X, Guo C, Fisher PB, Subjeck JR, Wang XY. Scavenger receptors: emerging roles in cancer biology and immunology. Adv Cancer Res 2015;128:309-364

14 Ramirez-Ortiz ZG, Pendergraft WF III, Prasad A, et al. The scavenger receptor SCARF1 mediates the clearance of apoptotic cells and prevents autoimmunity. Nat Immunol 2013;14(09):917-926

15 Wermeling F, Chen Y, Pikkarainen T, et al. Class A scavenger receptors regulate tolerance against apoptotic cells, and autoantibodies against these receptors are predictive of systemic lupus. J Exp Med 2007;204(10):2259-2265

16 Thanopoulou K, Fragkouli A, Stylianopoulou F, Georgopoulos S. Scavenger receptor class B type I (SR-BI) regulates perivascular macrophages and modifies amyloid pathology in an Alzheimer mouse model. Proc Natl Acad Sci U S A 2010;107(48):20816-20821

17 Rantakari P, Patten DA, Valtonen J, et al. Stabilin-1 expression defines a subset of macrophages that mediate tissue homeostasis and prevent fibrosis in chronic liver injury. Proc Natl Acad Sci U S A 2016;113(33):9298-9303

18 Kennedy DJ, Kashyap SR. Pathogenic role of scavenger receptor CD36 in the metabolic syndrome and diabetes. Metab Syndr Relat Disord 2011;9(04):239-245

19 El Khoury JB, Moore KJ, Means TK, et al. CD36 mediates the innate host response to $\beta$-amyloid. J Exp Med 2003;197(12):1657-1666

20 Armengol C, Bartolí R, Sanjurjo L, et al. Role of scavenger receptors in the pathophysiology of chronic liver diseases. Crit Rev Immunol 2013;33(01):57-96

21 Sørensen KK, McCourt P, Berg T, et al. The scavenger endothelial cell: a new player in homeostasis and immunity. Am J Physiol Regul Integr Comp Physiol 2012;303(12):R1217-R1230

22 Wilkinson AL, Qurashi M, Shetty S. The role of sinusoidal endothelial cells in the axis of inflammation and cancer within the liver. Front Physiol 2020;11:990 
23 Li R, Oteiza A, Sørensen KK, et al. Role of liver sinusoidal endothelial cells and stabilins in elimination of oxidized low-density lipoproteins. Am J Physiol Gastrointest Liver Physiol 2011;300(01):G71-G81

24 Politz O, Gratchev A, McCourt PA, et al. Stabilin-1 and -2 constitute a novel family of fasciclin-like hyaluronan receptor homologues. Biochem J 2002;362(Pt 1):155-164

25 Harris EN, Cabral F. Ligand binding and signaling of HARE/Stabilin-2. Biomolecules 2019;9(07):273

26 Witztum JL, Steinberg D. Role of oxidized low density lipoprotein in atherogenesis. J Clin Invest 1991;88(06):1785-1792

27 Schledzewski K, Géraud C, Arnold B, et al. Deficiency of liver sinusoidal scavenger receptors stabilin- 1 and -2 in mice causes glomerulofibrotic nephropathy via impaired hepatic clearance of noxious blood factors. J Clin Invest 2011;121(02):703-714

28 Malovic I, Sørensen KK, Elvevold KH, et al. The mannose receptor on murine liver sinusoidal endothelial cells is the main denatured collagen clearance receptor. Hepatology 2007;45(06): 1454-1461

29 Smedsrød B, Melkko J, Risteli L, Risteli J. Circulating C-terminal propeptide of type I procollagen is cleared mainly via the mannose receptor in liver endothelial cells. Biochem J 1990; 271(02):345-350

30 Elvevold K, Simon-Santamaria J, Hasvold H, McCourt P, Smedsrød B, Sørensen KK. Liver sinusoidal endothelial cells depend on mannose receptor-mediated recruitment of lysosomal enzymes for normal degradation capacity. Hepatology 2008;48(06): 2007-2015

31 Rijken DC, Otter M, Kuiper J, van Berkel TJ. Receptor-mediated endocytosis of tissue-type plasminogen activator ( $\mathrm{t}-\mathrm{PA}$ ) by liver cells. Thromb Res 1990;10:63-71

32 Martinez-Pomares L. The mannose receptor. J Leukoc Biol 2012; 92(06):1177-1186

33 Smedsrød B, Melkko J, Araki N, Sano H, Horiuchi S. Advanced glycation end products are eliminated by scavenger-receptormediated endocytosis in hepatic sinusoidal Kupffer and endothelial cells. Biochem J 1997;322(Pt 2):567-573

34 Lee SJ, Evers S, Roeder D, et al. Mannose receptor-mediated regulation of serum glycoprotein homeostasis. Science 2002;295 (5561):1898-1901

35 Pombinho R, Sousa S, Cabanes D. Scavenger receptors: promiscuous players during microbial pathogenesis. Crit Rev Microbiol 2018;44(06):685-700

36 Tripathi A, Debelius J, Brenner DA, et al. The gut-liver axis and the intersection with the microbiome. Nat Rev Gastroenterol Hepatol 2018;15(07):397-411

37 Broadley SP, Plaumann A, Coletti R, et al. Dual-track clearance of circulating bacteria balances rapid restoration of blood sterility with induction of adaptive immunity. Cell Host Microbe 2016;20 (01):36-48

38 Ishiguro T, Naito M, Yamamoto T, et al. Role of macrophage scavenger receptors in response to Listeria monocytogenes infection in mice. Am J Pathol 2001;158(01):179-188

39 Means TK, Mylonakis E, Tampakakis E, et al. Evolutionarily conserved recognition and innate immunity to fungal pathogens by the scavenger receptors SCARF1 and CD36. J Exp Med 2009; 206(03):637-653

40 Helmy KY, Katschke KJ Jr, Gorgani NN, et al. CRIg: a macrophage complement receptor required for phagocytosis of circulating pathogens. Cell 2006;124(05):915-927

41 Gorgani NN, He JQ Katschke KJ Jr, et al. Complement receptor of the Ig superfamily enhances complement-mediated phagocytosis in a subpopulation of tissue resident macrophages. J Immunol 2008;181(11):7902-7908

42 Zeng Z, Surewaard BG, Wong CH, Geoghegan JA, Jenne CN, Kubes P. CRIg functions as a macrophage pattern recognition receptor to directly bind and capture blood-borne gram-positive bacteria. Cell Host Microbe 2016;20(01):99-106
43 Heinsbroek SE, Taylor PR, Martinez FO, Martinez-Pomares L, Brown GD, Gordon S. Stage-specific sampling by pattern recognition receptors during Candida albicans phagocytosis. PLoS Pathog 2008;4(11):e1000218

44 Stewart CR, Stuart LM, Wilkinson K, et al. CD36 ligands promote sterile inflammation through assembly of a Toll-like receptor 4 and 6 heterodimer. Nat Immunol 2010;11(02):155-161

45 Heit B, Kim H, Cosío G, et al. Multimolecular signaling complexes enable Syk-mediated signaling of CD36 internalization. Dev Cell 2013;24(04):372-383

46 Triantafilou M, Gamper FG, Haston RM, et al. Membrane sorting of toll-like receptor (TLR)-2/6 and TLR2/1 heterodimers at the cell surface determines heterotypic associations with CD36 and intracellular targeting. J Biol Chem 2006;281(41):31002-31011

47 Murshid A, Borges TJ, Lang BJ, Calderwood SK. The scavenger receptor SREC-I cooperates with toll-like receptors to trigger inflammatory innate immune responses. Front Immunol 2016;7 (226):226

48 Jeannin P, Bottazzi B, Sironi M, et al. Complexity and complementarity of outer membrane protein A recognition by cellular and humoral innate immunity receptors. Immunity 2005;22 (05):551-560

49 Beauvillain C, Meloni F, Sirard J-C, et al. The scavenger receptors SRA-1 and SREC-I cooperate with TLR2 in the recognition of the hepatitis $C$ virus non-structural protein 3 by dendritic cells. J Hepatol 2010;52(05):644-651

50 Murshid A, Gong J, Prince T, Borges TJ, Calderwood SK. Scavenger receptor SREC-I mediated entry of TLR4 into lipid microdomains and triggered inflammatory cytokine release in RAW 264.7 cells upon LPS activation. PLoS One 2015;10(04):e0122529

51 Murshid A, Gong J, Ahmad R, Borges TJ, Calderwood SK. Scavenger receptor SREC-I promotes double stranded RNA-mediated TLR3 activation in human monocytes. Immunobiology 2015;220 (06):823-832

52 Komai K, Shichita T, Ito M, Kanamori M, Chikuma S, Yoshimura A. Role of scavenger receptors as damage-associated molecular pattern receptors in Toll-like receptor activation. Int Immunol 2017;29(02):59-70

53 Hawkes M, Li X, Crockett M, et al. CD36 deficiency attenuates experimental mycobacterial infection. BMC Infect Dis 2010;10 (01):299

54 Cha S-J, Park K, Srinivasan P, et al. CD68 acts as a major gateway for malaria sporozoite liver infection. J Exp Med 2015;212(09): 1391-1403

55 Guillot A, Tacke F. Liver macrophages: old dogmas and new insights. Hepatol Commun 2019;3(06):730-743

56 Yao Z, Mates JM, Cheplowitz AM, et al. Blood-borne lipopolysaccharide is rapidly eliminated by liver sinusoidal endothelial cells via high-density lipoprotein.J Immunol 2016;197(06):2390-2399

57 Ganesan LP, Mohanty S, Kim J, Clark KR, Robinson JM, Anderson CL. Rapid and efficient clearance of blood-borne virus by liver sinusoidal endothelium. PLoS Pathog 2011;7(09):e1002281

58 Mates JM, Yao Z, Cheplowitz AM, et al. Mouse liver sinusoidal endothelium eliminates HIV-like particles from blood at a rate of 100 million per minute by a second-order kinetic process. Front Immunol 2017;8:35

59 Uhrig A, Banafsche R, Kremer M, et al. Development and functional consequences of LPS tolerance in sinusoidal endothelial cells of the liver. J Leukoc Biol 2005;77(05):626-633

60 Patten DA, Kamarajah SK, Rose JM, et al. SCARF-1 promotes adhesion of $\mathrm{CD}^{+} \mathrm{T}$ cells to human hepatic sinusoidal endothelium under conditions of shear stress. Sci Rep 2017;7(01):17600

61 Øie CIWolfson DL, Yasunori T, et al. Liver sinusoidal endothelial cells contribute to the uptake and degradation of entero bacterial viruses. Sci Rep 2020;10(01):898

62 Cabral F, Al-Rahem M, Skaggs J, Thomas TA, Kumar N, Wu Q, Fadda P, Yu L, Robinson JM, (Lt.), Kim J, Jarjour WN, Rajaram MVS, Harris EN, Ganesan LP. Stabilin receptors clear LPS and control systemic 
inflammation. Last accessed on July 23, 2021 at SSRN: https://ssrn. com/abstract=3845681 or http://dx.doi.org/10.2139/ssrn.3845681

63 Limmer A, Ohl J, Kurts C, et al. Efficient presentation of exogenous antigen by liver endothelial cells to $\mathrm{CD} 8+\mathrm{T}$ cells results in antigen-specific T-cell tolerance. Nat Med 2000;6(12): 1348-1354

64 Schurich A, Böttcher JP, Burgdorf S, et al. Distinct kinetics and dynamics of cross-presentation in liver sinusoidal endothelial cells compared to dendritic cells. Hepatology 2009;50(03): 909-919

65 Shetty S, Lalor PF, Adams DH. Liver sinusoidal endothelial cells gatekeepers of hepatic immunity. Nat Rev Gastroenterol Hepatol 2018;15(09):555-567

66 Limmer A, Ohl J, Wingender G, et al. Cross-presentation of oral antigens by liver sinusoidal endothelial cells leads to CD8 T cell tolerance. Eur J Immunol 2005;35(10):2970-2981

67 Diehl L, Schurich A, Grochtmann R, Hegenbarth S, Chen L, Knolle PA. Tolerogenic maturation of liver sinusoidal endothelial cells promotes B7-homolog 1-dependent CD8+ T cell tolerance. Hepatology 2008;47(01):296-305

68 Berg M, Wingender G, Djandji D, et al. Cross-presentation of antigens from apoptotic tumor cells by liver sinusoidal endothelial cells leads to tumor-specific CD8 $+\mathrm{T}$ cell tolerance. Eur J Immunol 2006;36(11):2960-2970

69 Höchst B, Schildberg FA, Böttcher J, et al. Liver sinusoidal endothelial cells contribute to CD8 T cell tolerance toward circulating carcinoembryonic antigen in mice. Hepatology 2012;56(05):1924-1933

70 Fontana RJ. Acute liver failure including acetaminophen overdose. Med Clin North Am 2008;92(04):761-794, viii

71 Yoon E, Babar A, Choudhary M, Kutner M, Pyrsopoulos N. Acetaminophen-induced hepatotoxicity: a comprehensive update. J Clin Transl Hepatol 2016;4(02):131-142

72 Triantafyllou E, Woollard KJ, McPhail MJW, Antoniades CG, Possamai LA. The role of monocytes and macrophages in acute and acute-on-chronic liver failure. Front Immunol 2018;9:2948

73 Hiraoka A, Horiike N, Akbar SM, Michitaka K, Matsuyama T, Onji M. Soluble CD163 in patients with liver diseases: very high levels of soluble CD163 in patients with fulminant hepatic failure. J Gastroenterol 2005;40(01):52-56

74 Møller HJ, Grønbaek H, Schiødt FV, et al; U.S. Acute Liver Failure Study Group. Soluble CD163 from activated macrophages predicts mortality in acute liver failure. J Hepatol 2007;47(05): 671-676

75 Siggaard CB, Kazankov K, Rødgaard-Hansen S, et al. Macrophage markers soluble CD163 and soluble mannose receptor are associated with liver injury in patients with paracetamol overdose. Scand J Gastroenterol 2019;54(05):623-632

76 Grønbæk H, Rødgaard-Hansen S, Aagaard NK, et al; CANONIC study investigators of the EASL-CLIF Consortium. Macrophage activation markers predict mortality in patients with liver cirrhosis without or with acute-on-chronic liver failure (ACLF). J Hepatol 2016;64(04):813-822

77 Nielsen MC, Hvidbjerg Gantzel R, Clària J, Trebicka J, Møller HJ, Grønbæk H. Macrophage activation markers, CD163 and CD206, in acute-on-chronic liver failure. Cells 2020;9(05):1175

78 Zuo D, Yu X, Guo C, et al. Scavenger receptor A restrains T-cell activation and protects against concanavalin A-induced hepatic injury. Hepatology 2013;57(01):228-238

79 Labonte AC, Sung SJ, Jennelle LT, Dandekar AP, Hahn YS. Expression of scavenger receptor-AI promotes alternative activation of murine macrophages to limit hepatic inflammation and fibrosis. Hepatology 2017;65(01):32-43

80 Patten DA, Shetty S. More than just a removal service: scavenger receptors in leukocyte trafficking. Front Immunol 2018;9:2904

81 Patten DA, Shetty S. The role of Stabilin-1 in lymphocyte trafficking and macrophage scavenging in the liver microenvironment. Biomolecules 2019;9(07):283
82 Irjala H, Alanen K, Grénman R, Heikkilä P, Joensuu H, Jalkanen S. Mannose receptor (MR) and common lymphatic endothelial and vascular endothelial receptor (CLEVER)-1 direct the binding of cancer cells to the lymph vessel endothelium. Cancer Res 2003; 63(15):4671-4676

83 Irjala H, Elima K, Johansson EL, et al. The same endothelial receptor controls lymphocyte traffic both in vascular and lymphatic vessels. Eur J Immunol 2003;33(03):815-824

84 Salmi M, Koskinen K, Henttinen T, Elima K, Jalkanen S. CLEVER-1 mediates lymphocyte transmigration through vascular and lymphatic endothelium. Blood 2004;104(13):3849-3857

85 Karikoski M, Irjala H, Maksimow M, et al. Clever-1/Stabilin-1 regulates lymphocyte migration within lymphatics and leukocyte entrance to sites of inflammation. Eur J Immunol 2009;39 (12):3477-3487

86 Shetty S, Weston CJ, Adams DH, Lalor PF. A flow adhesion assay to study leucocyte recruitment to human hepatic sinusoidal endothelium under conditions of shear stress. J Vis Exp 2014;(85): 51330

87 Shetty S, Weston CJ, Oo YH, et al. Common lymphatic endothelial and vascular endothelial receptor-1 mediates the transmigration of regulatory $\mathrm{T}$ cells across human hepatic sinusoidal endothelium. J Immunol 2011;186(07):4147-4155

88 Shetty S, Bruns T, Weston CJ, et al. Recruitment mechanisms of primary and malignant B cells to the human liver. Hepatology 2012;56(04):1521-1531

89 Patten DA, Wilson GK, Bailey D, et al. Human liver sinusoidal endothelial cells promote intracellular crawling of lymphocytes during recruitment: a new step in migration. Hepatology 2017; 65(01):294-309

90 Falkowski M, Schledzewski K, Hansen B, Goerdt S. Expression of stabilin-2, a novel fasciclin-like hyaluronan receptor protein, in murine sinusoidal endothelia, avascular tissues, and at solid/liquid interfaces. Histochem Cell Biol 2003;120(05): 361-369

91 Jung MY, Park SY, Kim IS. Stabilin-2 is involved in lymphocyte adhesion to the hepatic sinusoidal endothelium via the interaction with alphaMbeta2 integrin. J Leukoc Biol 2007;82(05): 1156-1165

92 Géraud C, Koch P-S, Zierow J, et al. GATA4-dependent organspecific endothelial differentiation controls liver development and embryonic hematopoiesis. J Clin Invest 2017;127(03): 1099-1114

93 Shimaoka T, Nakayama T, Fukumoto N, et al. Cell surfaceanchored SR-PSOX/CXC chemokine ligand 16 mediates firm adhesion of CXC chemokine receptor 6-expressing cells. J Leukoc Biol 2004;75(02):267-274

94 Yamauchi R, Tanaka M, Kume $\mathrm{N}$, et al. Upregulation of SR-PSOX/CXCL16 and recruitment of CD8 $+\mathrm{T}$ cells in cardiac valves during inflammatory valvular heart disease. Arterioscler Thromb Vasc Biol 2004;24(02):282-287

95 Jiang X, Shimaoka T, Kojo S, et al. Cutting edge: critical role of CXCL16/CXCR6 in NKT cell trafficking in allograft tolerance. J Immunol 2005;175(04):2051-2055

96 Ruth JH, Haas CS, Park CC, et al. CXCL16-mediated cell recruitment to rheumatoid arthritis synovial tissue and murine lymph nodes is dependent upon the MAPK pathway. Arthritis Rheum 2006;54(03):765-778

97 Heydtmann M, Lalor PF, Eksteen JA, Hübscher SG, Briskin M, Adams DH. CXC chemokine ligand 16 promotes integrin-mediated adhesion of liver-infiltrating lymphocytes to cholangiocytes and hepatocytes within the inflamed human liver. J Immunol 2005;174(02):1055-1062

98 Sato T, Thorlacius H, Johnston B, et al. Role for CXCR6 in recruitment of activated CD8+ lymphocytes to inflamed liver. J Immunol 2005;174(01):277-283

99 Hudspeth K, Donadon M, Cimino M, et al. Human liver-resident CD56(bright)/CD16(neg) NK cells are retained within hepatic 
sinusoids via the engagement of CCR5 and CXCR6 pathways. J Autoimmun 2016;66:40-50

100 Stegmann KA, Robertson F, Hansi N, et al. CXCR6 marks a novel subset of T-bet(lo)Eomes(hi) natural killer cells residing in human liver. Sci Rep 2016;6(01):26157

101 Geissmann F, Cameron TO, Sidobre S, et al. Intravascular immune surveillance by CXCR6 + NKT cells patrolling liver sinusoids. PLoS Biol 2005;3(04):e113

102 Xu H-B, Gong Y-P, Cheng J, Chu Y-W, Xiong S-D. CXCL16 participates in pathogenesis of immunological liver injury by regulating $\mathrm{T}$ lymphocyte infiltration in liver tissue. World $\mathrm{J}$ Gastroenterol 2005;11(32):4979-4985

$103 \mathrm{Xu} \mathrm{H}, \mathrm{Xu} \mathrm{W}$, Chu Y, Gong Y, Jiang Z, Xiong S. Involvement of upregulated CXC chemokine ligand 16/scavenger receptor that binds phosphatidylserine and oxidized lipoprotein in endotoxin-induced lethal liver injury via regulation of T-cell recruitment and adhesion. Infect Immun 2005;73(07):4007-4016

104 Wang H, Shao Y, Zhang S, et al. CXCL16 deficiency attenuates acetaminophen-induced hepatotoxicity through decreasing hepatic oxidative stress and inflammation in mice. Acta Biochim Biophys Sin (Shanghai) 2017;49(06):541-549

105 Wehr A, Tacke F. The roles of CXCL16 and CXCR6 in liver inflammation and fibrosis. Curr Pathobiol Rep 2015;3(04): 283-290

106 Piccolo P, Vetrini F, Mithbaokar P, et al. SR-A and SREC-I are Kupffer and endothelial cell receptors for helper-dependent adenoviral vectors. Mol Ther 2013;21(04):767-774

107 Patten DA, Wilkinson AL, O'Rourke JM, Shetty S. Prognostic value and potential immunoregulatory role of SCARF1 in hepatocellular carcinoma. Front Oncol 2020;10:1947

108 Miyachi Y, Tsuchiya K, Komiya C, et al. Roles for cell-cell adhesion and contact in obesity-induced hepatic myeloid cell accumulation and glucose intolerance. Cell Rep 2017;18(11): 2766-2779

109 Shetty S, Lalor PF, Adams DH. Lymphocyte recruitment to the liver: molecular insights into the pathogenesis of liver injury and hepatitis. Toxicology 2008;254(03):136-146

110 Furuta K, Guo Q, Pavelko KD, et al. Lipid-induced endothelial vascular cell adhesion molecule 1 promotes nonalcoholic steatohepatitis pathogenesis. J Clin Invest 2021;131(06):143690

111 Thomas DL. Global elimination of chronic hepatitis. N Engl J Med 2019;380(21):2041-2050

112 Jefferies M, Rauff B, Rashid H, Lam T, Rafiq S. Update on global epidemiology of viral hepatitis and preventive strategies. World ] Clin Cases 2018;6(13):589-599

113 Ringehan M, McKeating JA, Protzer U. Viral hepatitis and liver cancer. Philos Trans R Soc Lond B Biol Sci 2017;372 (1732):20160274

114 Harvey CE, Post JJ, Palladinetti P, et al. Expression of the chemokine IP-10 (CXCL10) by hepatocytes in chronic hepatitis C virus infection correlates with histological severity and lobular inflammation. J Leukoc Biol 2003;74(03):360-369

115 Zeremski M, Petrovic LM, Talal AH. The role of chemokines as inflammatory mediators in chronic hepatitis $C$ virus infection. J Viral Hepat 2007;14(10):675-687

116 Li K, Li NL, Wei D, Pfeffer SR, Fan M, Pfeffer LM. Activation of chemokine and inflammatory cytokine response in hepatitis $C$ virus-infected hepatocytes depends on Toll-like receptor 3 sensing of hepatitis $C$ virus double-stranded RNA intermediates. Hepatology 2012;55(03):666-675

117 Shen W-J, Azhar S, Kraemer FBSR. SR-B1: a unique multifunctional receptor for cholesterol influx and efflux. Annu Rev Physiol 2018;80:95-116

118 Pileri P, Uematsu Y, Campagnoli S, et al. Binding of hepatitis C virus to CD81. Science 1998;282(5390):938-941

119 Scarselli E, Ansuini H, Cerino R, et al. The human scavenger receptor class B type $I$ is a novel candidate receptor for the hepatitis C virus. EMBO J 2002;21(19):5017-5025
120 Evans MJ, von Hahn T, Tscherne DM, et al. Claudin-1 is a hepatitis C virus co-receptor required for a late step in entry. Nature 2007; 446(7137):801-805

121 Ploss A, Evans MJ, Gaysinskaya VA, et al. Human occludin is a hepatitis $C$ virus entry factor required for infection of mouse cells. Nature 2009;457(7231):882-886

122 Bartosch B, Vitelli A, Granier C, et al. Cell entry of hepatitis C virus requires a set of co-receptors that include the CD81 tetraspanin and the SR-B1 scavenger receptor. J Biol Chem 2003;278(43): 41624-41630

123 Westhaus S, Deest M, Nguyen ATX, et al. Scavenger receptor class B member 1 (SCARB1) variants modulate hepatitis C virus replication cycle and viral load. J Hepatol 2017;67(02):237-245

124 Hsu C-S, Hsu S-J, Liu W-L, Chen D-S, Kao J-H. Association of SCARB1 gene polymorphisms with virological response in chronic hepatitis $C$ patients receiving pegylated interferon plus ribavirin therapy. Sci Rep 2016;6(01):32303

125 Sadeghi S, Davari M, Asli E, et al. Effect of IL15 rs10833 and SCARB1 rs10846744 on virologic responses in chronic hepatitis C patients treated with pegylated interferon- $\alpha$ and ribavirin. Gene 2017;630:28-34

126 Sulkowski MS, Kang M, Matining R, et al; AIDS Clinical Trials Group A5277 Protocol Team. Safety and antiviral activity of the HCV entry inhibitor ITX5061 in treatment-naive HCV-infected adults: a randomized, double-blind, phase $1 \mathrm{~b}$ study. J Infect Dis 2014;209(05):658-667

127 Rowe IA, Tully DC, Armstrong MJ, et al. Effect of scavenger receptor class B type I antagonist ITX5061 in patients with hepatitis $C$ virus infection undergoing liver transplantation. Liver Transpl 2016;22(03):287-297

128 Bataller R, Brenner DA. Liver fibrosis. J Clin Invest 2005;115(02): 209-218

129 Higashi T, Friedman SL, Hoshida Y. Hepatic stellate cells as key target in liver fibrosis. Adv Drug Deliv Rev 2017;121:27-42

130 Schneiderhan W, Schmid-Kotsas A, Zhao J, et al. Oxidized lowdensity lipoproteins bind to the scavenger receptor, CD36, of hepatic stellate cells and stimulate extracellular matrix synthesis. Hepatology 2001;34(4, Pt 1):729-737

131 Kang Q Chen A. Curcumin eliminates oxidized LDL roles in activating hepatic stellate cells by suppressing gene expression of lectin-like oxidized LDL receptor-1. Lab Invest 2009;89(11): $1275-1290$

132 Gieseler RK, Marquitan G, Schlattjan M, et al. Hepatocyte apoptotic bodies encasing nonstructural HCV proteins amplify hepatic stellate cell activation: implications for chronic hepatitis C. J Viral Hepat 2011;18(11):760-767

133 Schattenberg JM, Lazarus JV, Newsome PN, et al. Disease burden and economic impact of diagnosed non-alcoholic steatohepatitis in five European countries in 2018: a cost-of-illness analysis. Liver Int 2021;41(06):1227-1242

134 Govaere O, Martinez-Lopez N, Petersen SK, et al. Macrophage scavenger receptor 1 mediates lipid-induced inflammation in non-alcoholic fatty liver disease. bioRxiv 2020. Doi: 10.1101/2020.02.01.930115

135 Qiu Y, Liu S, Chen H-T, et al. Upregulation of caveolin-1 and SR-B1 in mice with non-alcoholic fatty liver disease. Hepatobiliary Pancreat Dis Int 2013;12(06):630-636

136 Hoekstra M, Ouweneel AB, Price J, et al. SR-BI deficiency disassociates obesity from hepatic steatosis and glucose intolerance development in high fat diet-fed mice. J Nutr Biochem 2021; 89:108564

137 Rada P, González-Rodríguez Á, García-Monzón C, Valverde ÁM Understanding lipotoxicity in NAFLD pathogenesis: is CD36 a key driver? Cell Death Dis 2020;11(09):802

138 Chabowski A, Żendzian-Piotrowska M, Konstantynowicz K, et al. Fatty acid transporters involved in the palmitate and oleate induced insulin resistance in primary rat hepatocytes. Acta Physiol (Oxf) 2013;207(02):346-357 
139 Li Y, Yang P, Zhao L, et al. CD36 plays a negative role in the regulation of lipophagy in hepatocytes through an AMPK-dependent pathway. J Lipid Res 2019;60(04):844-855

140 Strauss O, Phillips A, Ruggiero K, Bartlett A, Dunbar PR. Immunofluorescence identifies distinct subsets of endothelial cells in the human liver. Sci Rep 2017;7(01):44356

141 Kawanishi N, Mizokami T, Yada K, Suzuki K. Exercise training suppresses scavenger receptor CD36 expression in kupffer cells of nonalcoholic steatohepatitis model mice. Physiol Rep 2018;6 (23): $\mathrm{e} 13902$

142 Niu B, He K, Li P, et al. SIRT1 upregulation protects against liver injury induced by a HFD through inhibiting CD36 and the NFKB pathway in mouse Kupffer cells. Mol Med Rep 2018;18(02): 1609-1615

143 Couturier J, Nuotio-Antar AM, Agarwal N, et al. Lymphocytes upregulate CD36 in adipose tissue and liver. Adipocyte 2019;8 (01):154-163

144 Miquilena-Colina ME, Lima-Cabello E, Sánchez-Campos S, et al. Hepatic fatty acid translocase CD36 upregulation is associated with insulin resistance, hyperinsulinaemia and increased steatosis in non-alcoholic steatohepatitis and chronic hepatitis C. Gut 2011;60(10):1394-1402

145 Sheedfar F, Sung MM, Aparicio-Vergara M, et al. Increased hepatic CD36 expression with age is associated with enhanced susceptibility to nonalcoholic fatty liver disease. Aging (Albany NY) 2014;6(04):281-295

146 Zhang P, Ge Z, Wang H, et al. Prolactin improves hepatic steatosis via CD36 pathway. J Hepatol 2018;68(06):1247-1255

147 Koonen DP, Jacobs RL, Febbraio M, et al. Increased hepatic CD36 expression contributes to dyslipidemia associated with dietinduced obesity. Diabetes 2007;56(12):2863-2871

148 Wilson CG, Tran JL, Erion DM, Vera NB, Febbraio M, Weiss EJ. Hepatocyte-specific disruption of CD36 attenuates fatty liver and improves insulin sensitivity in HFD-fed mice. Endocrinology 2016;157(02):570-585

149 Handberg A, Højlund K, Gastaldelli A, et al; RISC Investigators. Plasma sCD36 is associated with markers of atherosclerosis, insulin resistance and fatty liver in a nondiabetic healthy population. J Intern Med 2012;271(03):294-304

150 Heebøll S, Poulsen MK, Ornstrup MJ, et al. Circulating sCD36 levels in patients with non-alcoholic fatty liver disease and controls. Int J Obes 2017;41(02):262-267

151 Ma C, Han M, Heinrich B, et al. Gut microbiome-mediated bile acid metabolism regulates liver cancer via NKT cells. Science 2018;360(6391):eaan5931

152 Karikoski M, Marttila-Ichihara F, Elima K, et al. Clever-1/stabilin1 controls cancer growth and metastasis. Clin Cancer Res 2014; 20(24):6452-6464

153 O'Rourke JM, Patten DA, Shetty S. Tumour-associated macrophages in hepatocellular carcinoma: pressing the metabolic switch to prevent T cell responses. J Hepatol 2019;71(02): 243-245

154 Yeung OWH, Lo C-M, Ling C-C, et al. Alternatively activated (M2) macrophages promote tumour growth and invasiveness in hepatocellular carcinoma. J Hepatol 2015;62(03):607-616

155 Kuang D-M, Zhao Q Peng C, et al. Activated monocytes in peritumoral stroma of hepatocellular carcinoma foster immune privilege and disease progression through PD-L1. J Exp Med 2009;206(06):1327-1337

156 Biswas SK, Gangi L, Paul S, et al. A distinct and unique transcriptional program expressed by tumor-associated macrophages (defective NF-kappaB and enhanced IRF-3/STAT1 activation). Blood 2006;107(05):2112-2122

157 Gordon S, Martinez FO. Alternative activation of macrophages: mechanism and functions. Immunity 2010;32(05):593-604

158 Dong P, Ma L, Liu L, et al. CD86+/CD206+, diametrically polarized tumor-associated macrophages, predict hepatocellular carcinoma patient prognosis. Int J Mol Sci 2016;17(03):320
159 Ren C-X, Leng R-X, Fan Y-G, et al. Intratumoral and peritumoral expression of CD68 and CD206 in hepatocellular carcinoma and their prognostic value. Oncol Rep 2017;38(02):886-898

160 Sica A, Saccani A, Bottazzi B, et al. Autocrine production of IL-10 mediates defective IL-12 production and NF-K B activation in tumor-associated macrophages. J Immunol 2000;164(02): 762-767

161 Monti P, Leone BE, Zerbi A, et al. Tumor-derived MUC1 mucins interact with differentiating monocytes and induce IL-10highIL12low regulatory dendritic cell. J Immunol 2004;172(12): 7341-7349

162 Jaynes JM, Sable R, Ronzetti M, et al. Mannose receptor (CD206) activation in tumor-associated macrophages enhances adaptive and innate antitumor immune responses. Sci Transl Med 2020; 12(530):eaax6337

163 Edin S, Wikberg ML, Dahlin AM, et al. The distribution of macrophages with a M1 or M2 phenotype in relation to prognosis and the molecular characteristics of colorectal cancer. PLoS One 2012;7(10):e47045

164 Fujimura T, Kambayashi Y, Furudate S, Kakizaki A, Aiba S. Immunomodulatory effect of bisphosphonate risedronate sodium on CD163+ arginase 1+ M2 macrophages: the development of a possible supportive therapy for angiosarcoma. Clin Dev Immunol 2013;2013:325412

165 Komohara Y, Niino D, Saito Y, et al. Clinical significance of $\mathrm{CD}_{163^{+}}$tumor-associated macrophages in patients with adult T-cell leukemia/lymphoma. Cancer Sci 2013;104(07): 945-951

166 Tiainen S, Tumelius R, Rilla K, et al. High numbers of macrophages, especially M2-like (CD163-positive), correlate with hyaluronan accumulation and poor outcome in breast cancer. Histopathology 2015;66(06):873-883

167 Kristiansen M, Graversen JH, Jacobsen C, et al. Identification of the haemoglobin scavenger receptor. Nature 2001;409 (6817):198-201

168 Schaer DJ, Alayash AI, Buehler PW. Gating the radical hemoglobin to macrophages: the anti-inflammatory role of CD163, a scavenger receptor. Antioxid Redox Signal 2007;9(07): 991-999

169 Philippidis P, Mason JC, Evans BJ, et al. Hemoglobin scavenger receptor CD163 mediates interleukin-10 release and heme oxygenase-1 synthesis: antiinflammatory monocyte-macrophage responses in vitro, in resolving skin blisters in vivo, and after cardiopulmonary bypass surgery. Circ Res 2004;94(01):119-126

170 Sierra-Filardi E, Vega MA, Sánchez-Mateos P, Corbí AL, PuigKröger A. Heme oxygenase-1 expression in M-CSF-polarized M2 macrophages contributes to LPS-induced IL-10 release. Immunobiology 2010;215(9-10):788-795

171 Weis N, Weigert A, von Knethen A, Brüne B. Heme oxygenase-1 contributes to an alternative macrophage activation profile induced by apoptotic cell supernatants. Mol Biol Cell 2009;20 (05):1280-1288

172 Bover LC, Cardó-Vila M, Kuniyasu A, et al. A previously unrecognized protein-protein interaction between TWEAK and CD163: potential biological implications. J Immunol 2007;178(12): 8183-8194

173 Motomura T, Shirabe K, Mano Y, et al. Neutrophil-lymphocyte ratio reflects hepatocellular carcinoma recurrence after liver transplantation via inflammatory microenvironment. J Hepatol 2013;58(01):58-64

174 Riabov V, Yin S, Song B, et al. Stabilin-1 is expressed in human breast cancer and supports tumor growth in mammary adenocarcinoma mouse model. Oncotarget 2016;7(21):31097-31110

175 Hollmén M, Figueiredo CR, Jalkanen S. New tools to prevent cancer growth and spread: a 'Clever' approach. Br J Cancer 2020; 123(04):501-509

176 Virtakoivu R, Rannikko J, Viitala M, et al. Systemic blockade of Clever-1 elicits lymphocyte activation alongside checkpoint 
molecule downregulation in patients with solid tumors: Results from a Phase I/II Clinical Trial. Clin Cancer Res 2021;June: OF1-OF16. Doi: 10.1158/1078-0432.CCR-20-4862

177 Seifert L, Deutsch M, Alothman S, et al. Dectin-1 regulates hepatic fibrosis and hepatocarcinogenesis by suppressing TLR4 signaling pathways. Cell Rep 2015;13(09):1909-1921

178 Liu M, Luo F, Ding C, et al. Dectin-1 activation by a natural product $\beta$-glucan converts immunosuppressive macrophages into an M1-like phenotype. J Immunol 2015;195(10):5055-5065

179 Chiba S, Ikushima H, Ueki H, et al. Recognition of tumor cells by Dectin-1 orchestrates innate immune cells for anti-tumor responses. eLife 2014;3:e04177

180 Mattiola I, Tomay F, De Pizzol M, et al. The macrophage tetraspan MS4A4A enhances dectin-1-dependent NK cell-mediated resistance to metastasis. Nat Immunol 2019;20(08):1012-1022

181 Shi B, Abrams M, Sepp-Lorenzino L. Expression of asialoglycoprotein receptor 1 in human hepatocellular carcinoma. J Histochem Cytochem 2013;61(12):901-909

182 Witzigmann D, Quagliata L, Schenk SH, Quintavalle C, Terracciano LM, Huwyler J. Variable asialoglycoprotein receptor 1 expression in liver disease: Implications for therapeutic intervention. Hepatol Res 2016;46(07):686-696

183 Steirer LM, Park EI, Townsend RR, Baenziger JU. The asialoglycoprotein receptor regulates levels of plasma glycoproteins terminating with sialic acid $\alpha 2,6$-galactose. J Biol Chem 2009; 284(06):3777-3783

184 Park EI, Mi Y, Unverzagt C, Gabius H-J, Baenziger JU. The asialoglycoprotein receptor clears glycoconjugates terminating with sialic acid $\alpha 2,6 \mathrm{GalNAc}$. Proc Natl Acad Sci U S A 2005;102 (47):17125-17129

$185 \mathrm{Gu} \mathrm{D}$, Jin H, Jin G, et al. The asialoglycoprotein receptor suppresses the metastasis of hepatocellular carcinoma via LASS2mediated inhibition of V-ATPase activity. Cancer Lett 2016;379 (01):107-116

186 Xiao Y, Chen B, Yang K, et al. Down-regulation of MARCO associates with tumor progression in hepatocellular carcinoma. Exp Cell Res 2019;383(02):111542

187 Beattie L, Sawtell A, Mann J, et al. Bone marrow-derived and resident liver macrophages display unique transcriptomic signatures but similar biological functions. J Hepatol 2016;65(04): 758-768

188 Sun H, Song J, Weng C, et al. Association of decreased expression of the macrophage scavenger receptor MARCO with tumor progression and poor prognosis in human hepatocellular carcinoma. J Gastroenterol Hepatol 2017;32(05):1107-1114

189 Stephen SL, Freestone K, Dunn S, et al. Scavenger receptors and their potential as therapeutic targets in the treatment of cardiovascular disease. Int J Hypertens 2010;2010:646929-646929

190 Vasquez M, Simões I, Consuegra-Fernández M, Aranda F, Lozano F, Berraondo P. Exploiting scavenger receptors in cancer immunotherapy: lessons from CD5 and SR-B1. Eur J Immunol 2017;47 (07):1108-1118

191 Enciu AM, Radu E, Popescu ID, Hinescu ME, Ceafalan LC. Targeting CD36 as biomarker for metastasis prognostic: how far from translation into clinical practice? BioMed Res Int 2018; 2018:7801202

192 Aizarani N, Saviano A, Sagar, Mailly L, Durand S, Herman JS, Pessaux P, Baumert TF, Grün D. A human liver cell atlas reveals heterogeneity and epithelial progenitors. Nature 2019;572 (7768):199-204

193 Ramachandran P, Dobie R, Wilson-Kanamori JR, et al. Resolving the fibrotic niche of human liver cirrhosis at single-cell level. Nature 2019;575(7783):512-518

194 Dobie R, Wilson-Kanamori JR, Henderson BEP, et al. Single-cell transcriptomics uncovers zonation of function in the mesenchyme during liver fibrosis. Cell Rep 2019;29(07):1832.e8-1847.e8

195 Wang H, Thorling CA, Liang X, et al. Diagnostic imaging and therapeutic application of nanoparticles targeting the liver. J Mater Chem B Mater Biol Med 2015;3(06):939-958

196 Hayashi Y, Takamiya M, Jensen PB, et al. Differential nanoparticle sequestration by macrophages and scavenger endothelial cells visualized in vivo in real-time and at ultrastructural resolution. ACS Nano 2020;14(02):1665-1681

197 Allen RJ, Mathew B, Rice KG. PEG-peptide inhibition of scavenger receptor uptake of nanoparticles by the liver. Mol Pharm 2018; 15(09):3881-3891

198 Campbell F, Bos FL, Sieber S, et al. Directing nanoparticle biodistribution through evasion and exploitation of Stab2-dependent nanoparticle uptake. ACS Nano 2018;12(03):2138-2150

199 Arias-Alpizar G, Koch B, Hamelmann NM, et al. Stabilin-1 is required for the endothelial clearance of small anionic nanoparticles. Nanomedicine (Lond) 2021;34:102395

200 Miller CM, Donner AJ, Blank EE, et al. Stabilin-1 and Stabilin-2 are specific receptors for the cellular internalization of phosphorothioate-modified antisense oligonucleotides (ASOs) in the liver. Nucleic Acids Res 2016;44(06):2782-2794

201 Gökirmak T, Nikan M, Wiechmann S, Prakash TP, Tanowitz M, Seth PP. Overcoming the challenges of tissue delivery for oligonucleotide therapeutics. Trends Pharmacol Sci 2021;42(07):588-604

202 Willoughby JLS, Chan A, Sehgal A, et al. Evaluation of GalNAcsiRNA conjugate activity in pre-clinical animal models with reduced asialoglycoprotein receptor expression. Mol Ther 2018;26(01):105-114

203 Graversen JH, Svendsen P, Dagnæs-Hansen F, et al. Targeting the hemoglobin scavenger receptor CD163 in macrophages highly increases the anti-inflammatory potency of dexamethasone. Mol Ther 2012;20(08):1550-1558

204 Svendsen P, Graversen JH, Etzerodt A, et al. Antibody-directed glucocorticoid targeting to CD163 in M2-type macrophages attenuates fructose-induced liver inflammatory changes. Mol Ther Methods Clin Dev 2016;4:50-61

205 Etzerodt A, Tsalkitzi K, Maniecki M, et al. Specific targeting of $\mathrm{CD}_{163}{ }^{+}$TAMs mobilizes inflammatory monocytes and promotes T cell-mediated tumor regression. J Exp Med 2019;216 (10):2394-2411

206 Pellicoro A, Ramachandran P, Iredale JP, Fallowfield JA. Liver fibrosis and repair: immune regulation of wound healing in a solid organ. Nat Rev Immunol 2014;14(03):181-194 